\title{
Fluorescent sensors for ions based on organic structures
}

\author{
Emma B. Veale* and Thorfinnur Gunnlaugsson* \\ DOI: $10.1039 / \mathbf{c 0 0 4 1 4 6 g}$
}

This report highlights some of the developments in 2009 of fluorescent, and in some cases, dual fluorescent and colorimetric, sensors, that are based on organic structures, and that were developed for the sensing/recognition of anions and cations.

\section{Introduction}

Anions are ubiquitous in nature and in biological processes and they are also implicated in industrial and agricultural pollution. Hence, development of selective optical signalling systems for their easy detection has received considerable attention in recent decades. In the past it has been shown that fluorescent sensors are attractive tools for ion recognition because of their high sensitivity at low analyte concentration. This report will provide an overview of organic receptor systems that exhibit a fluorescent emission change response upon the recognition of anions or cations.

The first section deals with receptors designed for the recognition of simple anions, such as fluoride, cyanide, acetate and phosphate whereas the second and later sections will focus on fluorescent anion sensors based on naphthalimides and calixarenes while FRET based anion sensors will also be reviewed.

Unlike the field of anion sensing by organic molecules, the field of cation sensing is well established and has been extensively reviewed in the past. To date, a large effort has been devoted to the development of sensors for group I and group II metal cations, particularly for ions that are of critical physiological importance such as $\mathrm{Na}^{+}, \mathrm{K}^{+}, \mathrm{Mg}^{2+}$ and $\mathrm{Ca}^{2+}$, as well as protons. While many examples of sensors for these ions were published in the 2009 literature, the emphasis on the sensing of transition metal ions has become ever greater, particularly as their role in physiological and neurological processes has become ever more apparent. In 2009, far more examples of sensors for d-metal ions were developed than for group I and II metal ions. Partly, this is due to the better understanding of their biological roles that has been achieved through the development of d-metal targeting receptors, sensors and imaging agents, based on organic structures. Their role in heavy industry, etc., also makes them a prime target in the monitoring of environmentally important ions. In contrast to anion sensing, the field of cation sensing remains more prolific and hence, it will only be possible to present a fraction of the many examples published in 2009. Moreover, because of the clear trend discussed above, this section will highlight the area of d-metal ion sensing, rather than group I and II metal cation sensing, although the latter will commence the cation section.

School of Chemistry, Centre for Synthesis and Chemical Biology, Trinity College Dublin, Dublin 2, Ireland.E-mail: eveale@tcd.ie, gunnlaut@tcd.ie; Fax: + 3531716 2428; Tel: +35318963459 


\section{Fluorescent organic sensors for anions}

Lin and co-workers have developed several structurally simple systems for the detection of biologically relevant anions, which, depending upon the host:guest combination, exhibit varying degrees of fluorescent and colorimetric changes upon the recognition of various anions. One such design utilised a novel positive homotropic allosteric system based on the 3-methylpyrozole-5-one-4-one-2',4'dinitrophenylhydrazone $\mathbf{1}$, for both colorimetric and fluorescent anion detection and sensing. ${ }^{1}$ In the case of $\mathrm{F}^{-}$, the sensor 1 under physiological condition (pH 7.4) exhibited significant enhancement of fluorescence emission upon anion recognition, which the authors attributed to both a Photoinduced Electron Transfer (PET) mechanism and also an anion binding induced rigidity of $\mathbf{1}$. The sensor $\mathbf{1}$ also exhibited a two step colorimetric recognition process, firstly by hydrogen bonding with the anion, which gave rise to an obvious colour change from yellow to orange; this was then followed by a second recognition step which involved the hydrazone from of $\mathbf{1}$ changing to the azo form, which was accompanied by a further colour change from orange to purple.
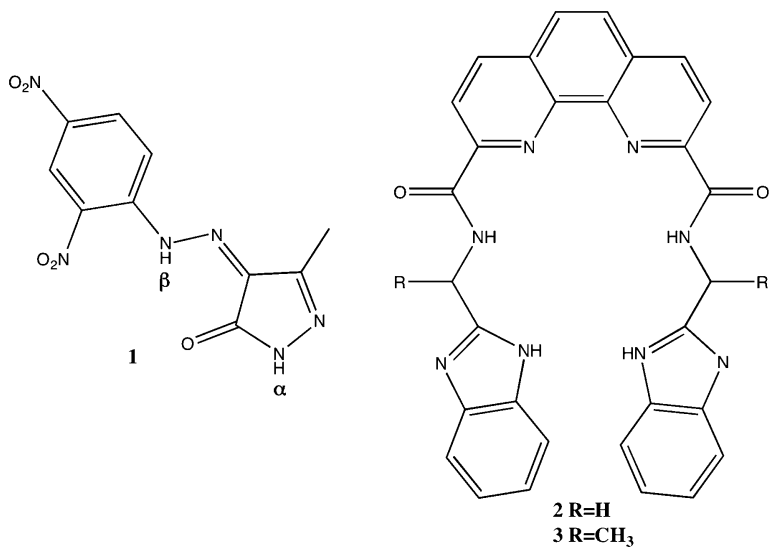<smiles>O=c1[nH]c2ccc([N+](=O)[O-])cc2[nH]c1=O</smiles>

The two neutral fluorescent anion sensors $\mathbf{2}$ and $\mathbf{3}$, containing the benzimidazole receptor and 1,10-phenanthroline fluorophore, respectively, were also developed by the same group and found to display both "positive" and "negative" fluorescence responses depending on the anion being detected. ${ }^{2}$ For both $\mathbf{2}$ and $\mathbf{3}$, the binding to more basic anions such as $\mathrm{F}^{-}$and $\mathrm{AcO}^{-}$, gave rise to a quenching in the fluorescence emission while an enhancement in the fluorescence emission occurred upon interaction with $\mathrm{Cl}^{-}, \mathrm{Br}^{-}$and $\mathrm{I}^{-}$. The differing responses for $\mathbf{2}$ and $\mathbf{3}$ was attributed to a PET quenching mechanism upon binding with $\mathrm{F}^{-}$and $\mathrm{AcO}^{-}$while the recognition of $\mathrm{Cl}^{-} \mathrm{Br}^{-}$and $\mathrm{I}^{-}$gave rise an increase in the rigidity of $\mathbf{2}$ and $\mathbf{3}$, resulting in an emission "turn-on" effect. The same group has reported on the development of the simple amide-based colorimetric and fluorescent anion chemosensor 6-nitro-1,4-dihydro-quinoxaline-2,3-dione, 4, which exhibited significant PET quenching of its fluorescence emission upon binding to anions such as $\mathrm{F}^{-}$and $\mathrm{AcO}^{-}{ }^{3}$ It was also reported that the change was accompanied by a distinct colour 
change from colourless to yellow in DMSO, due to the deprotonation of Yliew adratide Online protons by the more basic anion, $\mathrm{F}^{-}$; this was confirmed by using ${ }^{1} \mathrm{H}$ NMR titration experiments.

\section{Detection of cyanide}

Pollution by cyanide anion can have a detrimental effect on biology and the environment, as it is extremely toxic to mammals. The recognition of cyanide has been achieved in the past by utilization of hydrogen binding interactions or nucleophilic addition of cyanide as a means of minimizing interference from other anions. With this in mind, Guo and co-workers have developed two novel fluorescent probes, 5 and $\mathbf{6}$, bearing salicylaldehyde hydrazone functionality as binding site for the selective detection of cyanide. ${ }^{4}$ In DMSO-aqueous media, both 'sensors' were found to exhibit significant fluorescence enhancement in the presence of cyanide and such an effect was attributed to nucleophilic attack of the anion on the imine group of the probe (in a $1: 1$ binding stoichiometry). It was also found that sensor 6 was capable of serving as a "naked-eye" indicator for cyanide, by exhibiting a colour change from colourless to yellow upon binding with the anion. Another method for the selective sensing of cyanide has been achieved through utilization of copper-cyanide affinity, to give rise to potential "Off-On" type fluorescent sensors selective for cyanide. Recently Chung et al. developed a fluorescein- $\mathrm{Cu}^{2+}$ derivative, $7-\mathrm{Cu}^{2+}$ which, at $\mathrm{pH} 7.4$ in water, exhibited dramatic switching on of its fluorescence emission in the presence of cyanide. ${ }^{5}$ This sensing system was also further applied to a microfluidic platform, whereby $7-\mathrm{Cu}^{2+}$ displayed green fluorescence upon the addition of cyanide and this then led to the in vivo imaging of cyanide.
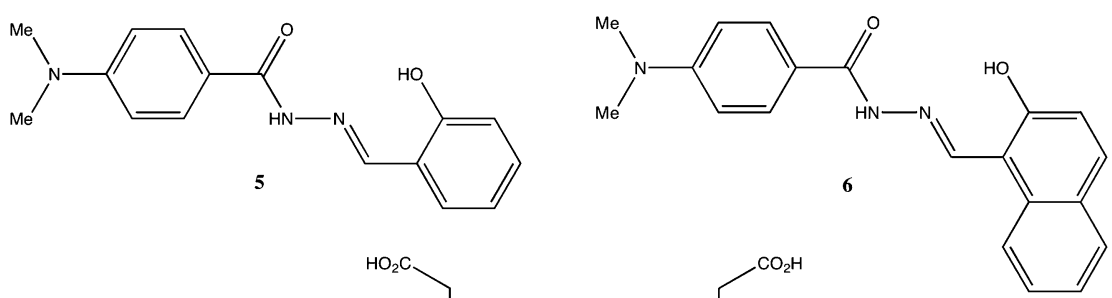<smiles>O=C(O)CN(CC(=O)O)Cc1c2oc3c(CN(CC(=O)O)CC(=O)O)c(O)c(Cl)cc3c(-c3ccccc3C(=O)O)c-2cc(Cl)c1=O</smiles>

\section{Detection of fluoride}

The detection of fluoride anion is of particular importance due to its essential role in reducing tooth decay, for the treatment of osteoporosis and also its association with nerve gas agents. To achieve such selective detection various fluorescent and 
colorimetric sensors have been developed to date. Shiraishi et al., madeiegwrecteple Online contribution to this area of research, through the development of the indole-azadiene conjugate 1,4-bis(3-indolyl)-2,3-diaza-1,3-butadiene, $\mathbf{8}$, which was shown to act as an efficient fluorescent and colorimetric probe for fluoride in DMSO. ${ }^{6}$ A selective colour change from colourless to yellow with the appearance of a green fluorescence was exhibited by $\mathbf{8}$ in the presence of $\mathrm{F}^{-}$and such changes were attributed to an interaction between the indolic $\mathrm{NH}$ proton and $\mathrm{F}^{-}$, as confirmed by ${ }^{1} \mathrm{H} \mathrm{NMR}$ analysis and $a b$ initio calculations. The addition of other anions such as $\mathrm{Cl}^{-}, \mathrm{Br}^{-}, \mathrm{I}^{-}$, $\mathrm{AcO}^{-}, \mathrm{ClO}_{4}{ }^{-}, \mathrm{H}_{2} \mathrm{PO}_{4}{ }^{-} \mathrm{HSO}_{4}{ }^{-}, \mathrm{NO}_{3}{ }^{-}$and $\mathrm{SCN}^{-}$, to a solution of 8 in DMSO, did not show any absorbance or fluorescence spectral change.

Griesbeck et al., achieved selective fluoride recognition, by using the chemosensor 9 which is based on a chiral urea-phthalimide conjugate. ${ }^{7}$ Upon recognition of $\mathrm{F}^{-}$, the sensor 9 was reported to exhibit changes in both its absorption and fluorescence spectra when recorded in acetonitrile solution. Upon titration with $\mathrm{F}^{-}$, the absorption spectrum of 9 was red-shifted with the appearance of three isosbestic points at 258, 317 and $342 \mathrm{~nm}$, respectively while its emission spectrum $\left(\lambda_{\text {exc }}=340 \mathrm{~nm}\right)$ exhibited a complete switching-off of emission intensity upon increasing concentration of $\mathrm{F}^{-}$. Such emission changes were attributed to a static quenching mechanism, supported by the appearance of a new CT complex emission at a longer wavelength, and also by the fact that no there were no changes in the singlet excited state lifetime of 9 in the presence of $\mathrm{F}^{-}$. The recognition of $\mathrm{F}^{-}$by 9 was also shown to be through $\mathrm{H}$-bonding interactions rather than deprotonation, according to ${ }^{1} \mathrm{H}$ NMR studies and theoretical calculations based on DFT methods.

The cleft-shaped anion sensor, 10, containing amide and hydroxyl as recognition units was developed and synthesised by Bao et al., for the selective detection of $\mathrm{F}^{-8}$. The sensor 10 was capable of detecting $\mathrm{F}^{-}$in DMSO solution with fluorescence enhancement and visible naked-eye colour change from colorless to yellow-green, both of which were attributed to multiple H-bonding interactions. It was also found that the recognition of $\mathrm{F}^{-}$was reversible as the addition of a protic solvent to a solution of $\mathbf{1 0}$ bound to $\mathrm{F}^{-}$, changed the colour of the solution back to colourless.
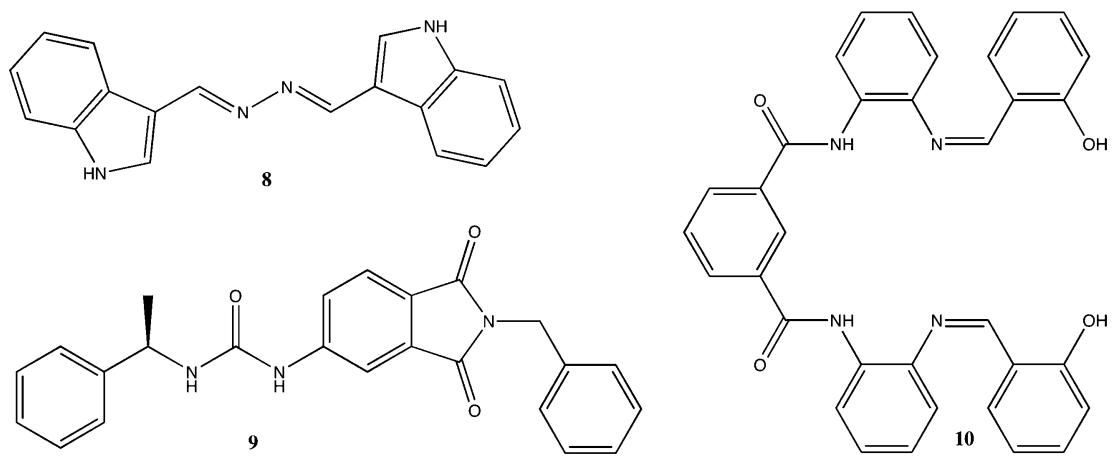

Another efficient fluorescent sensor for fluoride reported in 2009, is that based on the core-substituted naphthalene diimide sensor 11, bearing a bis-sulfonamide group. ${ }^{9}$ Upon titration of $\mathrm{F}^{-}$by a solution of $\mathbf{1 1}$ in $\mathrm{CHCl}_{3}$, significant quenching $(97 \%)$ of emission intensity occurred and subsequent Job's plot analysis indicated the formation of a $2: 1$ complex with association constant in the range of $10^{5} \mathrm{M}^{-2}$. In comparison, less significant emission quenching occurred in the presence of all 
other anions tested. It was also shown by ${ }^{1} \mathrm{H}$ NMR studies that the selectiVitymfortifte Online at micromolar concentration in $\mathrm{CHCl}_{3}$ occurred by a two-stage deprotonation process, which led to the resultant colorimetric detection of $\mathrm{F}^{-}$by 11 ; this involved a colour change from blue to green and was found also to be reversible upon addition of a protic solvent.<smiles>CCCCCN1C(=O)c2c(Br)c(Br)c3c4c(c5c(c(c24)C1=O)Cc1cc(NS(=O)(=O)c2ccc(C)cc2)c(NS(=O)(=O)c2ccc(C)cc2)cc1C5)C(=O)N(CCC)C3=O</smiles>

\section{Naphthalimide-based fluorescent sensors for anions}

Gunnlaugsson et al., have been actively involved in the development of fluorescent sensors for anions and in the last few years have reported on a series of charge neutral urea- and thiourea-based 4-amino-1,8-naphthalimide fluorescent PET and colorimetric sensors for anion recognition. Some of these sensors were designed on the "fluorophore-spacer-receptor" principle with the receptor moieties being functionalised at the 4-position of the aryl ring. In general it is the "push-pull" nature of the Internal Charge Transfer (ICT) excited state of the 4-amino-1,8naphthalimide fluorophore which favours PET quenching by electron rich receptors when they are located at the 4-position of the aryl ring. In 2009, the same group reported that fluorescent PET anion sensing in 4-amino-1,8-naphthalimide based thiourea anion sensors can in fact be achieved when the same electron rich receptor moiety is positioned at the imide site. ${ }^{10}$ In their report, the photophysical properties of sensors 12-16 in DMSO were analysed and compared upon binding to biologically relevant anions, such as acetate, hydrogen phosphate and fluoride. It was found that both $\mathbf{1 5}$ and $\mathbf{1 6}$, with the thiourea moiety connected to the imide site, behaved as efficient PET sensors, as anion recognition resulted in significant quenching of the fluorescence emission with little or no change in their absorption spectra, in the same manner as occurred for related compounds. Furthermore, the structural isomers $\mathbf{1 3}$ and $\mathbf{1 5}$ showed the same affinity for $\mathrm{AcO}^{-}, \mathrm{H}_{2} \mathrm{PO}_{4}^{-}$and $\mathrm{F}^{-}$. Also in the presence of an excess of $\mathrm{F}^{-}$, both sensors exhibited colour changes from green to purple indicative of deprotonation of the $\mathrm{N}-\mathrm{H}$ of the more acidic 4-amino naphthalimide moiety.

Using a fluorophore ${ }_{1}$-spacer-receptor-spacer-fluorophore ${ }_{2}$ principle, Pischel et al., developed tristable fluorescent $\mathrm{pH}$ sensor/switch $17 .{ }^{11}$ The structure is composed of a 4-amino-1,8-naphthalimide fluorophore linked via a central tertiary amine aliphatic spacer chain, to an un-substituted 1,8-naphthalimide fluorophore. This sensor was designed to act as a molecule logic gate mimic so that the fluorescence emission intensity would be modulated upon protonation and deprotonation of the central tertiary amine unit with $\mathrm{H}^{+}$and $\mathrm{F}^{-}$ions in $\mathrm{MeCN}$, respectively. Upon protonation, 
<smiles>CCN1C(=O)c2cccc3c(NCc4ccc(NC(=S)Nc5ccc(P)cc5)cc4)ccc(c23)C1=O</smiles>

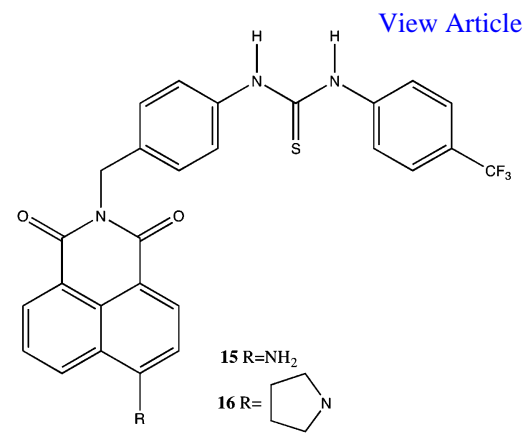

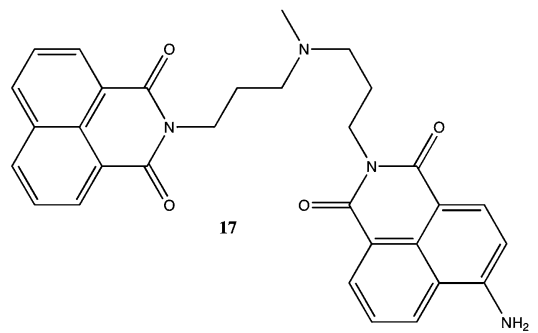

PET quenching of the 1,8-naphthalimide fluorophore was blocked, resulting in an electronic energy transfer (EET) between the two fluorophores. Using $\mathrm{F}^{-}$as a strong base, subsequent deprotonation of the tertiary amine reactivated PET, which resulted in efficient emission quenching. Deprotonation of the 4-amino-naphthalimide moiety resulted at higher concentration of $\mathrm{F}^{-}$which in turn gave rise to further emission quenching ( $c a .93 \%$ ). By using the fluoride anion as an input, the authors classified this system as being a ternary NOR logic gate mimic.

This review has focused on the developments of fluorescent chemosensors for the selective detection of various anions based on small molecule sensors, but within the 2009 literature some reports on the development of fluorescent polymer sensors for anions have further emerged. For instance, Tian et al. reported on the development of the novel polyphenylacetylene $\mathbf{1 8}$ containing naphthalimide units as a ratiometric fluorescent chemosensor for fluoride in acetonitrile solution. ${ }^{12}$ The utility of the naphthalimide fluorophore in anion sensing is well documented (as discussed above), and the structure itself is normally functionalised at the 4-position of the naphthalimide ring with electron donating groups to give rise to an efficient Internal Charge Transfer (ICT) excited state, which can be easily modulated and monitored upon the selective detection of anions. Indeed, it was found that $\mathbf{1 8}$, functionalised by an amido moiety at the 4-position of the aryl ring, was capable of detecting fluoride in acetonitrile at concentrations in the range of $10-100 \mu \mathrm{m}$, by exhibiting noticeable changes in its fluorescence spectrum in a wavelength-ratiometric manner, due to an enhanced ICT excited state upon deprotonation of the amide $\mathrm{NH}$ by $\mathrm{F}^{-}$. Upon titration of $\mathrm{F}^{-}$, the emission spectrum of $\mathbf{1 8}$ exhibited a large decrease in emission intensity, with formation of a red-shifted emission band and a concomitant isoemissive point. Furthermore, in the presence of 10 equivalents of $\mathrm{F}^{-}$, sensor $\mathbf{1 8}$ showed a colourless to yellow colour change and also blue to orange emission colour change, which was visible to the naked eye. Importantly, prior to anion sensing analysis, it was shown that both the absorption and fluorescence bands of the naphthalimide side chain units were only slightly affected by the presence of the 
polyphenylacetylene backbone through electronic interaction in the grdinid Adtacte Online and a slight quenching of naphthalimide emission in the excited state.

Building on this work, Tian et al. utilized the 4-amido functionalised naphthalimide structure in $\mathbf{1 8}$ for the development of the polymer chemosensor 19, which was synthesised by reversible addition-fragmentation chain transfer (RAFT) polymerization, for the selective detection of $\mathrm{F}^{-}$anion. ${ }^{13}$ It was found in their studies that 19, when analysed in a $\mathrm{CH}_{2} \mathrm{Cl}_{2}-\mathrm{DMSO}(9: 1 \mathrm{v} / \mathrm{v})$ solvent mixture, exhibited noticeable changes in both its fluorescence and absorption spectra upon interaction with $\mathrm{F}^{-}$, which were also accompanied by colourless to yellow colour changes, which were visible to the naked eye. As for sensors 12-16 and 17 such fluorescent and colorimetric changes were again attributed to deprotonation of the amino moiety at the 4-position of the aryl ring, which in turn gave, rise to an enhancement of the "push-pull" nature of the naphthalimide ICT excited state. Other halides tested induced no effect on the ground or excited state properties of $\mathbf{1 9 .}$ Furthermore, it was shown that the highest molecular weight polymer form of $\mathbf{1 9}$ showed more significant emission enhancement in the presence of $\mathrm{F}^{-}$in comparison to its monomer counterpart, justifying such a design feature and the utility of RAFT polymerization in the development of efficient polymer fluoride sensors.

With this in mind and motivated towards incorporating receptors onto a polymeric framework for the generation of a polymeric platform with multiple anion binding sites, Callan et al., have incorporated a polymerisable 1,8-naphthalimide based thiourea sensor, into a poly(mercaptopropyl-methyl) siloxane (PMPMS) giving rise to the polymer-bound fluorescent sensor 20. ${ }^{14}$ Compound $\mathbf{2 0}$ revealed that it is a more efficient anion binder in comparison with its monomer form, by exhibiting substantial changes in its fluorescence spectrum, in particular upon titration with $\mathrm{F}^{-}$ in either DMSO or MeCN solutions, which gave rise to efficient quenching of the naphthalimide emission. Addition of chloride, bromide or hydrogensulfate gave rise to no changes in the emission spectrum of $\mathbf{2 0}$ in DMSO, but acetate and dihydrogenphosphate gave rise to some quenching of emission intensity ( $\mathrm{ca} .40 \%)$. It was postulated that the DMSO solvent assisted the binding of $\mathrm{F}^{-}$between the adjacent thiourea residues of $\mathbf{2 0}$.

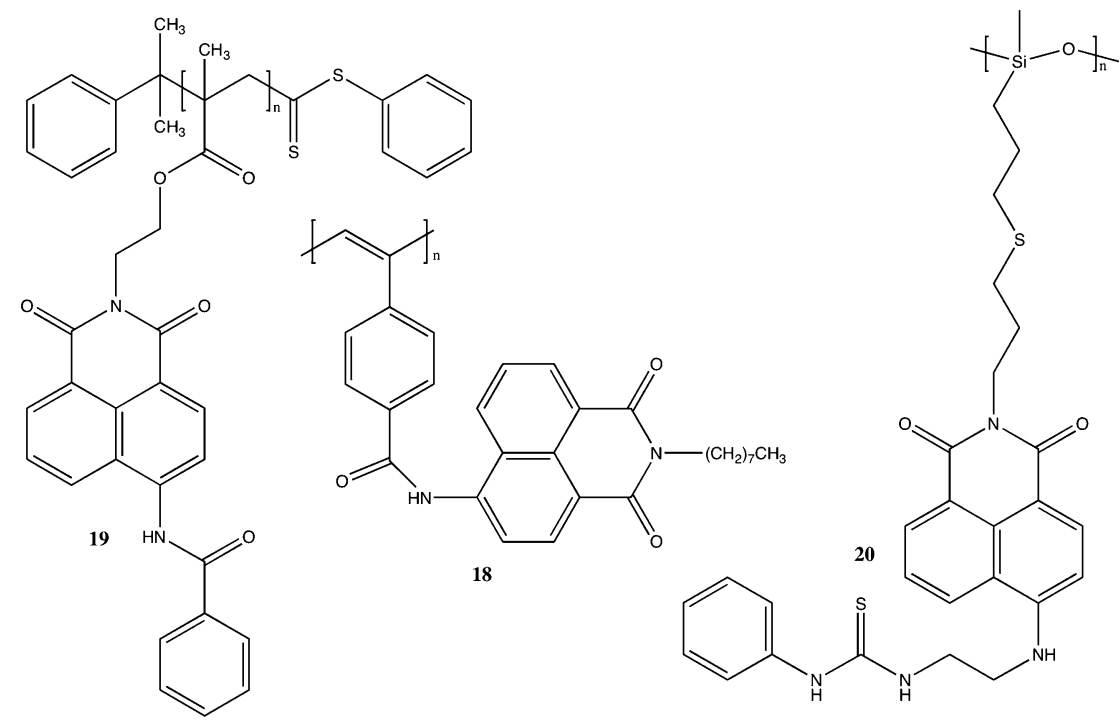


Wei and Jia et al. have recently designed and developed the low-moleculierwetighle Online organogelators (LMOGs) $\mathbf{2 1}$ and $\mathbf{2 2}$ as potential fluorescent sensor materials for the selective naked-eye detection of $\mathrm{F}^{-15}$. ${ }^{2}$ Both sensors were found to exhibit variations in their gelling and sensing behaviour with $\mathbf{2 1}$ and $\mathbf{2 2}$ being more effective in aromatic and protic solvents, respectively. For example, sensor $\mathbf{2 1}$ was found to easily gelate in toluene, and upon the addition of $\mathrm{F}^{-}$(0.5 eq.) the gel transformed into solution due to disruption of intermolecular hydrogen-binding interactions. In comparison, upon addition of $\mathrm{F}^{-}$the alcohol gel of 22 was unaffected but in $\mathrm{MeCN}$ the fluorescent emission intensity of $\mathbf{2 2}$ was found to be effectively "switched-on" and also red-shifted by $60 \mathrm{~nm}$, which the authors attributed to conformational changes and hydrogen-bonding interactions between the urea groups and $\mathrm{F}^{-}$.

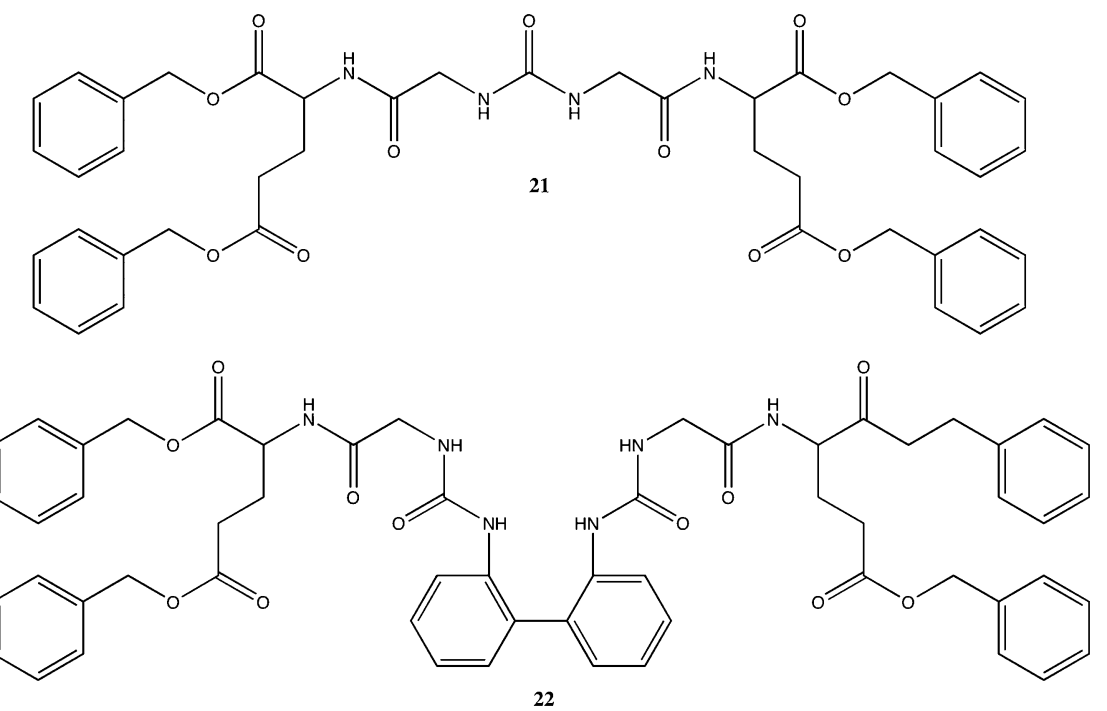

The ratiometric fluorescence sensing of $\mathrm{F}^{-}$was achieved by Yoon and James et al., by the development of a series of boronic acid containing imidazolium based anion receptors, 23-25. ${ }^{16}$ The receptors simply differed by having the phenylboronic acid linked either ortho (23), meta (24) or para (25) to the naphthoimidazolium moiety through a methylene group. Indeed it was found that receptor $\mathbf{2 3}$ exhibited enhanced fluoride binding in comparison to $\mathbf{2 4}$ and $\mathbf{2 5}$, while it was also confirmed that the formation of $(\mathrm{C}-\mathrm{H})^{+} \ldots \mathrm{F}^{-}$type ionic hydrogen bond with the imidazolium moiety only occurred after the addition of $\mathrm{F}^{-}$to the boron centre. It was also reported that receptor 23 was capable of sensing $\mathrm{F}^{-}$in aqueous solution $\left(95: 5 \mathrm{CH}_{3} \mathrm{CN} / \mathrm{HEPES}\right.$ mixture) by exhibiting ratiometric fluorescence emission changes, and that it did not exhibit any changes for any of the other anions tested.

$\mathrm{Yu}$ et al., have also reported on the use of imidazolium-based receptors as fluorescent sensors for fluoride. In their work, they designed and synthesised the novel imidazolium-functionalized BINOL fluorescent receptor 26, which proved to act as a fluorescent and colorimetric sensor for fluoride and acetate in $\mathrm{MeCN} .{ }^{17} \mathrm{In}$ fact this particular sensor could selectively detect fluoride over acetate, proven as being due to a unique fluoride induced charge-transfer emission response. Further studies also showed that $\mathbf{2 6}$ could enantioselectively bind $t$-Boc alanine, showing the utility of such a structure in the further development of chiral anion sensors. ${ }^{18}$ 

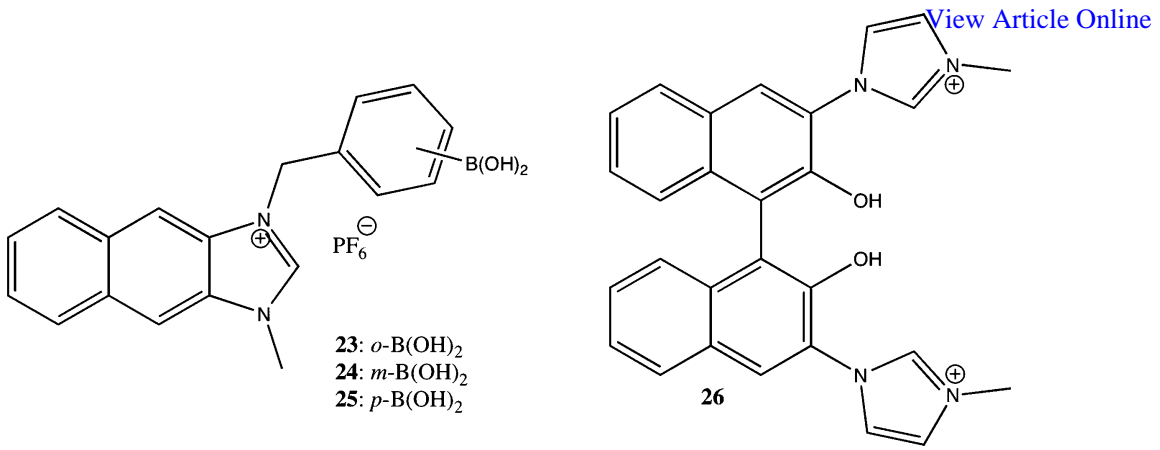

The fluorescent sensors 27-29 based on carbazolylurea anion receptors were designed by Gale et al. for the selective detection of oxo-anions. ${ }^{19}$ Indeed, it was found that sensor $\mathbf{2 7}$ has a higher affinity for benzoate, exhibiting efficient fluorescence quenching in DMSO-0.5\% water solution upon titration with tetrabutylammonium benzoate, in comparison with sensor $\mathbf{2 8}$ or 29. Furthermore, less fluorescence quenching of $\mathbf{2 7}$ was observed in the presence of acetate, fluoride, chloride and dihydrogen phosphate.<smiles>O=C(Nc1cccc2c1[nH]c1ccccc12)Nc1cccc2c1[nH]c1ccccc12</smiles><smiles>O=C(Nc1cccc2cc[nH]c12)Nc1cccc2c1[nH]c1ccccc12</smiles><smiles>O=C(Nc1ccccc1)Nc1cccc2c1[nH]c1ccccc12</smiles>

Goswami et al. developed the new selenium metal-based fluorescent sensor, 5-pivaloylamino-1,2,5-selenodiazolo[3,4-d]pyrimidin-7-(6H)-one 30, for the sensing of both monocarboxylic acids and carboxylate anions in $\mathrm{CHCl}_{3} \cdot{ }^{20} \mathrm{In}$ their studies it was reported that $\mathbf{3 0}$ was capable of detecting carboxylate anions over monocarboxylic acids and that sensor $\mathbf{3 0}$ was also selective for more hindered carboxylate anions by exhibiting pronounced red-shifts accompanied by an enhancement in the emission intensity in its fluorescence spectrum. A binding constant of $K_{\mathrm{a}}=5.21 \times 10^{3} \mathrm{M}^{-1}( \pm 0.3)$ was determined using the fluorescence emission data for the binding of $\mathbf{3 0}$ with adamantane1-carboxylate, which is an order of magnitude higher than the $\mathrm{K}_{\mathrm{a}}$ which was determined for the binding of $\mathbf{3 0}$ with phenyl acetate. The receptor also showed a colour change, which was visible to the naked eye in the presence of carboxylate anions.

For the selective recognition of phosphate anion, Jang and co-workers, reported on a novel benzthiazole-based fluorescent receptor $\mathbf{3 1}$ and compared its binding ability with that of $\mathbf{3 2}$ and $\mathbf{3 3}{ }^{21}$ It was found that the selective recognition of dihydrogen phosphate by 31 in $\mathrm{CH}_{3} \mathrm{CN} / \mathrm{DMSO} / \mathrm{H}_{2} \mathrm{O}(98: 1: 1, \mathrm{v} / \mathrm{v} / \mathrm{v})$ buffered solution was due to strong hydrogen bonding, resulting from a deficiency in cooperative polarization effect induced by the amide groups. A Job's plot analysis confirmed that dihydrogen phosphate formed a $1: 1$ complex with $\mathbf{3 1}$ with an association 
<smiles></smiles>

30<smiles>O=C(Nc1nc2ccccc2s1)c1cccc(C(=O)Nc2nc3ccccc3s2)c1</smiles><smiles>O=C(Nc1nc2ccccc2[nH]1)c1cccc(C(=O)Nc2nc3ccccc3[nH]2)c1</smiles><smiles>O=C(Nc1nc2ccccc2s1)c1ccccc1</smiles>

constant $\mathrm{K}$, calculated as $7.9 \times 10^{3} \mathrm{M}^{-1}( \pm 1.3)$ from the titration results. In their previous studies it was reported that receptor 32 interacted strongly with several anions, but did not exhibit any selectivity whereas sensor $\mathbf{3 3}$ did not bind any anions tested.

As a means of investigating the binding ability of pyridinium amides in anion recognition, Ghosh et al. have reported on the design and development of an anthracene-based macrocyclic receptor $\mathbf{3 4}$ for the selective recognition of 1,4phenylenediacetate. ${ }^{22}$ It was found that anion binding at the charged sites of the receptor in $\mathrm{CH}_{3} \mathrm{CN}$ lead to efficient "switching-on" of emission due to an inhibition

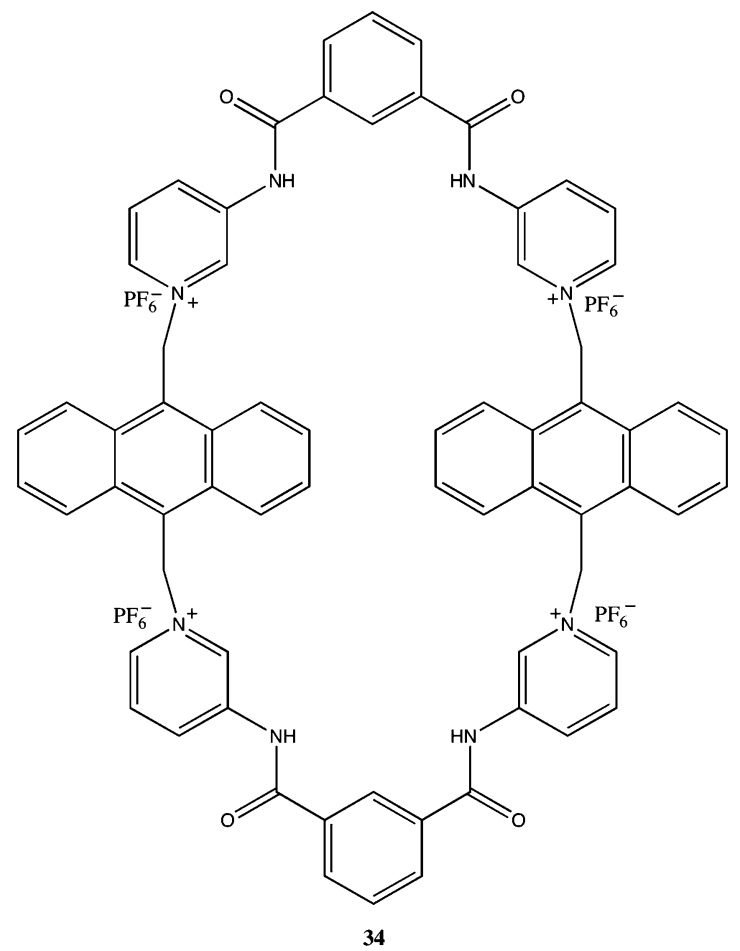


of PET and Job plot analysis showed the formation of $1: 1$ binding stoikirionetifye Online with 1,4-phenylenediacetate, and a $K_{\mathrm{a}}=3.34 \times 10^{5} \mathrm{M}^{-1}$. Furthermore, upon the binding of 34 with 1,4-phenylenediacetate, pimelate and terephthalate, the formation of a new emission band at longer wavelengths was observed indicating the formation of an excimer between the anthracenes in 34. In comparison, the emission intensity of 34 was unaffected in the presence of smaller dicarboxylates, such as acetate, benzoate and malonate. Overall the authors attributed the strong anion binding ability of 34 with 1,4-phenylenediacetate to the synergistic effect of hydrogen bonding, weak $\pi$-stacking and charge-charge interactions.

\section{FRET sensors for the detection of anions}

$\mathrm{Fu}$ et al. reported on a new anthracene based fluorescent chemodosimeter $\mathbf{3 5}$ containing a guanidinio-carbonylpyrrole moiety for the selective recognition of sulfite in aqueous solution. ${ }^{23}$ Compound $\mathbf{3 5}$ was designed so that spectral overlap between the guanidiniocarbonyl pyrrole emission and the anthracene absorption would make intramolecular fluorescence energy transfer (FRET) occur between the two fluorophores and indeed when analysed, 35 was shown to exhibit efficient FRET ratiometric fluorescence changes for sulfite over other anions, (such as $\mathrm{F}^{-}, \mathrm{Cl}^{-}, \mathrm{Br}^{-}$, $\mathrm{I}^{-}, \mathrm{AcO}^{-}, \mathrm{SO}_{4}{ }^{2-}, \mathrm{HCO}_{3}{ }^{-}, \mathrm{HPO}_{4}{ }^{2-}, \mathrm{P}_{2} \mathrm{O}_{7}{ }^{4-}, \mathrm{NO}_{3}{ }^{-}$and $\mathrm{NO}_{2}{ }^{-}$) in $90 \%$ water/DMSO solution (10 mM Tris- $\mathrm{HCl}$ buffer, $\mathrm{pH}$ 7.2). Here, the changes in the emission spectrum of 35 observed upon addition of sulfite involved a decrease in the emission intensity of the anthracene fluorophore with a concomitant increase in the emission intensity of the guanidiniocarbonylpyrrole moiety along with the formation of an isoemissive point. A rationale given for such ratiometric fluorescence changes was that the rate of the photodimerization reaction of $\mathbf{3 5}$ was enhanced upon the binding of the sulfite anion. Job plot analysis confirmed a $1: 1$ binding stoichiometry and from the above changes, a binding constant $K_{\mathrm{a}}=104 \mathrm{M}^{-1}$ was determined. It was also reported that a quenching of the anthracene emission occurred in the presence of both nitrite and nitrate, but without any increase in the guanidiniocarbonylpyrrole emission, which was indicative of a less effective FRET between the two adjacent fluorophores.

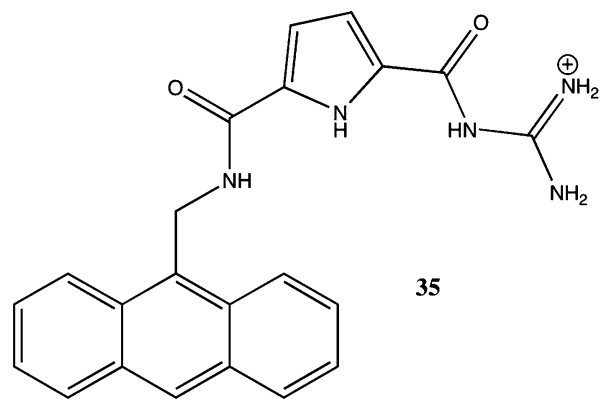

Fang et al. utilised a FRET mechanism for the selective detection of geranyl pyrophosphate in DMSO over other anions through the design of a chemosensing ensemble comprising a hexaamide receptor $\mathbf{3 6}$ and coumarin phosphate $\mathbf{3 7}$, whereby the FRET was found to be diminished upon the displacement of $\mathbf{3 7}$ by isoprenyl pyrophosphates (GPP). ${ }^{24}$ It was shown that upon complexation the fluorescence spectra of 36 exhibited a decrease in the monomer emission of the pyrenes with concomitant increase in the coumarin emission, confirming a FRET process. Furthermore, from analysis of the fluorescence and NMR spectroscopy data, the 
hexaamide receptor was found to bind GGP in a $1: 1$ stoichiometry with an Wsisociattiok Online constant of $2.3( \pm 0.8) \times 10^{4} \mathrm{M}^{-1}$. The authors speculated that such binding occurred via multiple hydrogen bonding interactions within the pseudotetrahedral cleft of $\mathbf{3 6}$ and also by hydrophobic interactions with the aliphatic chains of $\mathbf{3 6}$.

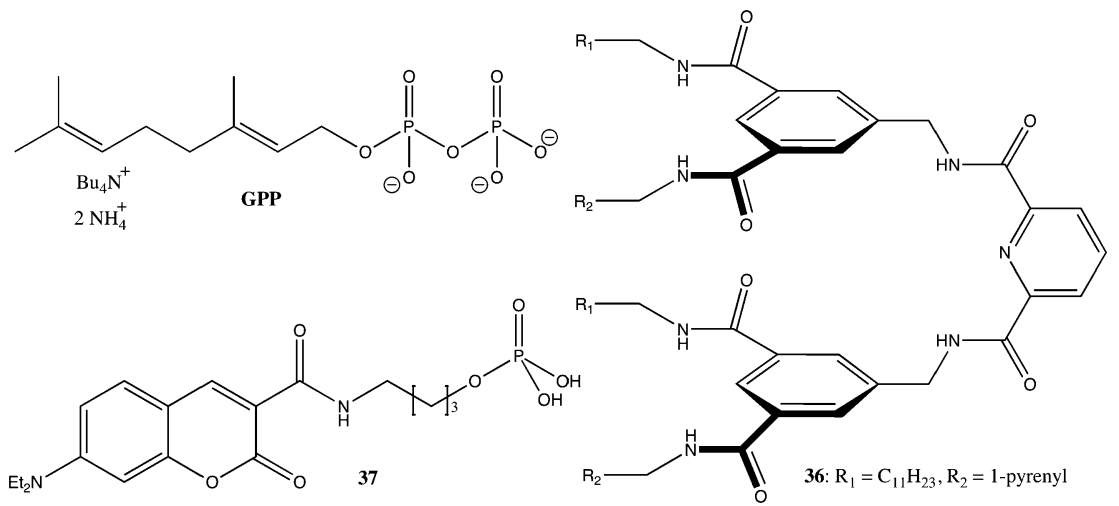

\section{Fluorescent anion sensors based on calix[4]arenes}

Calix[4]arenes have been widely used as anion chemosensors based on the fact that they are large in size and also have varied conformational flexibilities which endows them with pronounced anion binding ability. In 2009, Kim et al. reported on the development of the fluorescent chemosensor $\mathbf{3 8}$ which has two amidoanthraquinones linked at the lower rim of a $p$-tert-butylcalix[4]arene by amido groups. ${ }^{25}$ Excited state studies showed that 38 exhibited a binding preference for $\mathrm{F}^{-}$over other anions tested $\left(\mathrm{Cl}^{-}, \mathrm{Br}^{-}, \mathrm{I}^{-}, \mathrm{CH}_{3} \mathrm{COO}^{-}, \mathrm{H}_{2} \mathrm{PO}_{4}^{-}, \mathrm{HSO}_{4}^{-}\right.$and $\left.\mathrm{OH}^{-}\right)$with a $K_{\mathrm{a}}$ of $2.79 \times 10^{2} \mathrm{M}^{-1}$ for a $1: 1$ binding stoichiometry. Upon titration with $\mathrm{F}^{-}$, the fluorescence emission intensity of 38 in $\mathrm{CH}_{3} \mathrm{CN}$ was found to increase, and was accompanied by a colour change from colourless to green. The authors suggested that the high selectivity of $\mathbf{3 8}$ for $\mathrm{F}^{-}$could be attributed to an inhibition of the Excited State Intramolecular Proton Transfer (ESIPT) process due to fluoride-induced H-bonding and subsequent deprotonation of the amide moieties of the two amidoanthraquinones.
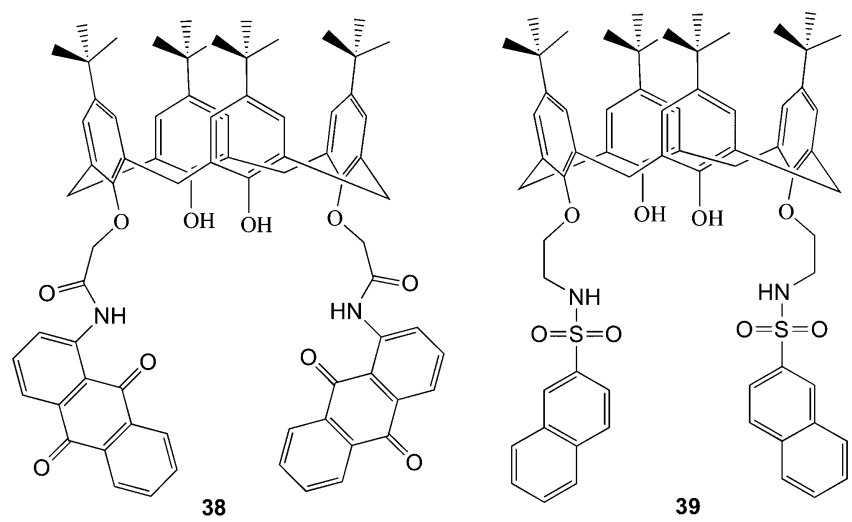

The calix[4]arene derivative 39 containing naphthalene sulfonyl amide groups for anion recognition was reported by Liu et al. ${ }^{26}$ It was shown that 39 was capable of 
binding strongly with $\mathrm{F}^{-}$and $\mathrm{AcO}^{-}$in DMSO solution, exhibitingiexffietiegle Online quenching of emission due to an enhanced PET mechanism, but it was found to bind the same anions weakly in $\mathrm{CHCl}_{3}$. The rationale given was that $\mathbf{3 9}$ assumes a different configuration depending on the solvent used, whereby the two lower-rim naphthalene groups exist in the distal form in polar solutions, resulting in $\mathbf{3 9}$ only exhibiting monomer fluorescence emission. However, it takes the $\pi-\pi$ dimer form in apolar solution, so that both monomer and excimer emissions were also observed. The emission data for the binding of 39 with $\mathrm{F}^{-}$was fitted to a $1: 1$ host-guest stoichiometry using a nonlinear least squares method, giving rise to complex stability constants of $K_{\mathrm{s}}=16300 \pm 800 \mathrm{M}^{-1}$ and $900 \pm 80 \mathrm{M}^{-1}$ in DMSO and $\mathrm{CHCl}_{3}$ solutions, respectively. The calix[4]arene 39 was found to bind less efficiently with anions such as $\mathrm{Cl}^{-}, \mathrm{Br}^{-}, \mathrm{HSO}_{4}^{-}$and $\mathrm{H}_{2} \mathrm{PO}_{4}^{-}$, regardless of the solvent medium.

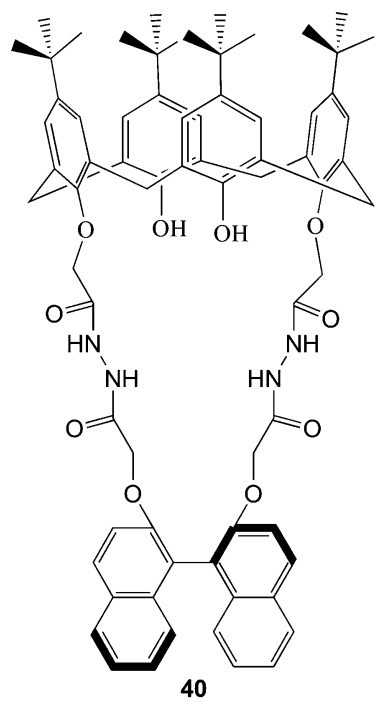<smiles></smiles>

(S)-41<smiles>O=C(c1ccccc1)c1cc2ccccc2c(-c2c(O)c(C(=O)c3ccccc3)cc3ccccc23)c1O</smiles>

$(R)-41$

For the enantioselective recognition of chiral dicarboxylate anions, such as $N$-Boc- $D$ - and $L$-glutamate, $N$-Boc- $D$ - and $L$-aspartate, $D$ - and $L$-tartrate, $D$ - and $L$-malate, the novel chiral calix[4]arene containing $S$-Binol fluorescent receptor $\mathbf{4 0}$ was designed, synthesised and analysed using fluorescence and ${ }^{1} \mathrm{H}$ NMR spectroscopy by $\mathrm{He}$ et al. ${ }^{27}$ It was discovered that $\mathbf{4 0}$ was capable of forming a $1: 1$ binding stoichiometric complex with $N$-Boc- $L$ - or $D$-glutamate in DMSO, and that it also exhibited varying degrees of emission quenching in the presence of either enantiomer with enantioselectivity being reported as $K_{\mathrm{ass}(\mathrm{L})} / K_{\mathrm{ass}(\mathrm{D})}=4.65$. The binding interaction of $\mathbf{4 0}$ with the other chiral dicarboxylate anions was shown not to occur in an enantioselective manner, but did result in similar quenching of emission to that for $\mathrm{N}$-Boc-glutamate. The binding of $\mathbf{4 0}$ to $\mathrm{N}$-Boc-glutamate was shown to occur by multiple hydrogen bonding interactions.

Following this report and by excluding the use of the large cavity size of calix[4]arenes, Wang et al. reported on the development of the Binol containing benzyl unit derivatives, $\mathbf{4 1}$, as enantioselective fluorescent sensors for various chiral carboxylates, such as mandelate, $N$-Boc-alanine and $N$-Boc-phenylalanine. ${ }^{28}$ It was shown that both $(S)-\mathbf{4 1}$ and $(R)-\mathbf{4 1}$ were capable of binding to the amino acid enantiomers in a $1: 1$ complex stoichiometry, but with different degrees of 
fluorescence quenching, thus exhibiting efficient enantioselective recognitibisubitticgle Online In fact, for $(S)$-41 the quenching efficiency of the $(S)$-amino acids was significantly higher than that of the $(R)$-amino acid anions; analogously, $(R)-\mathbf{4 1}$ showed greater enantioselectivity for the $(R)$-amino acids over the $(S)$-amino acids, probably due to their complementary structures. Nevertheless, both $(S)-\mathbf{4 1}$ and $(R)-\mathbf{4 1}$ showed poor enantioselectivity for mandelate with a $K_{\mathrm{ass}(\mathrm{L})} / K_{\mathrm{ass}(\mathrm{D})}=1.05$ being reported for $(S)-41$, in contrast to a much more efficient enantioselective recognition of the phenylalanine enantiomers with a reported $K_{\mathrm{ass}(\mathrm{L})} / K_{\mathrm{ass}(\mathrm{D})}=7.38$.

For the enantioselective recognition of tartaric acid, James and Zhao et al. reported on the development of the 3,6-disubstituted carbazole-based bisboronic acid fluorescent sensor $42 .{ }^{29}$ At neutral pH, 42 exhibited an enhancement or a reduction in fluorescence emission, dependant upon recognition of the different tartaric enantiomers. However, the fluorescence intensity was found to be unusually $\mathrm{pH}$ dependent, being either reduced or enhanced at acidic or basic $\mathrm{pH}$, respectively, with a reverse PET mechanism from the fluorophore to the protonated amine/ phenylboronic acid being proposed for such an effect.

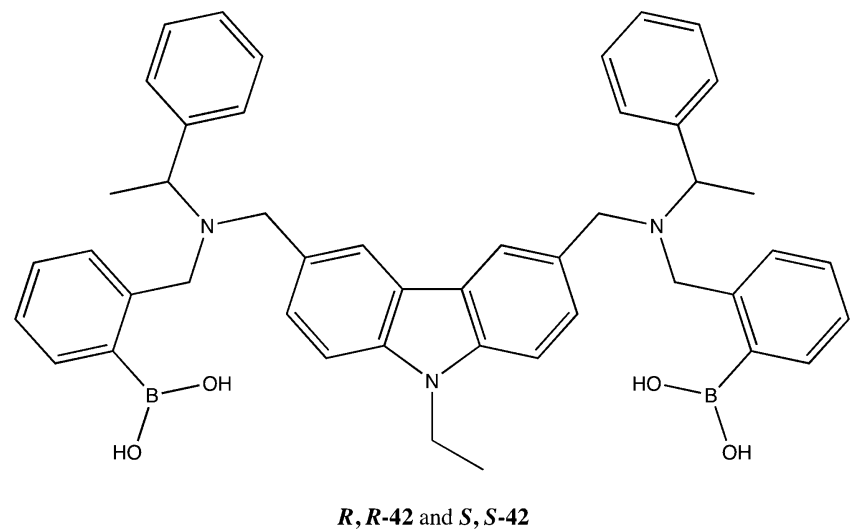

\section{Thiourea-based fluorescent sensors for amino acid recognition}

Achieving molecular recognition of biologically relevant anions, such as amino acids, using fluorescent sensors has been an active area of research within supramolecular chemistry. Tuntulani et al. reported on the development of the acridinium based fluorescent sensor $\mathbf{4 3}$ and its cyclic derivative 44, both containing thiourea anion recognition moieties. ${ }^{30}$ The anion binding ability of both $\mathbf{4 3}$ and $\mathbf{4 4}$ with $L$-Trp, -Phe, -Leu, -Ala and -Gly (in their unprotected form) were studied and compared with their charge neutral acridine precursors using NMR, UV-Vis and fluorescence spectroscopy. It was found that both the protonated 43 and $\mathbf{4 4}$ exhibited efficient binding (in a $1: 1$ binding stoichiometry) with amino acids compared with the charge neutral derivatives, and that greater selectivity was exhibited towards $L$-Trp with calculated binding constants of $K=2873$ and $3157 \mathbf{M}^{-1}$ for $\mathbf{4 3}$ and $\mathbf{4 4}$, respectively. In general, both $\mathbf{4 3}$ and $\mathbf{4 4}$ showed large enhancements in their emission spectra in the presence of the studied amino acids, with the largest enhancement being observed for the aromatic amino acids, $L$-Trp and $L$-Phe. It was speculated by the authors that such efficient amino acid recognition by these charged fluorescent sensors was due predominately to strong electrostatic and hydrogen bonding interactions. 
<smiles>O=C([O-])C(F)(F)F</smiles>

43

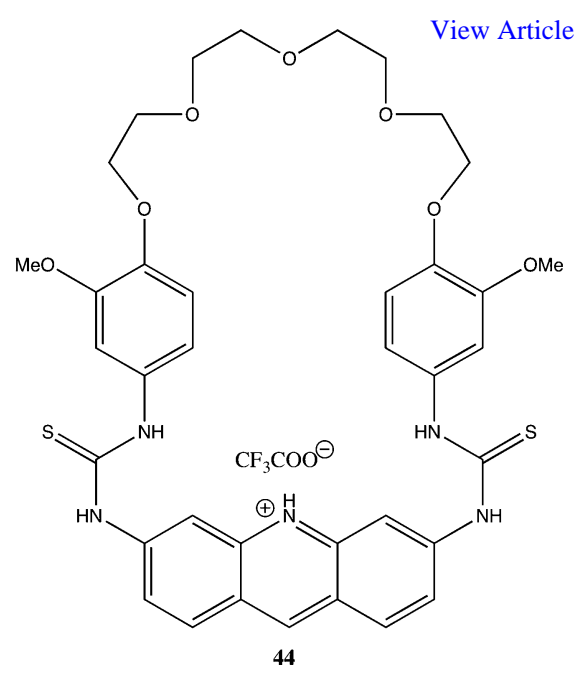

For the enantioselective recognition of the amino acid $\alpha$-phenylglycine, the charge neutral thiourea based fluorescent PET chemosensor $\mathbf{4 5}$ was developed and analysed using UV/Vis absorption and fluorescence spectroscopy. ${ }^{31}$ It was reported that an enhancement in the emission intensity of $\mathbf{4 5}$ was observed in the presence of the phenylglycine enantiomers possibly due to a diminished PET process caused by interaction of the anion with the thiourea and indole moieties. Furthermore, $\mathbf{4 5}$ showed a greater increase in emission intensity in the presence of $L$-phenylglycine over $D$-phenylglycine with the enantioselectivity being reported as $K_{\mathrm{ass}(\mathrm{L})} / K_{\mathrm{ass}(\mathrm{D})}=$ 5.64. The addition of $L$-phenylglycine to a DMSO solution of $\mathbf{4 5}$ also resulted in a colour change of yellow to orange-red, which was visible to the naked eye, and the colour change was found to be reversed upon addition of protic solvents.

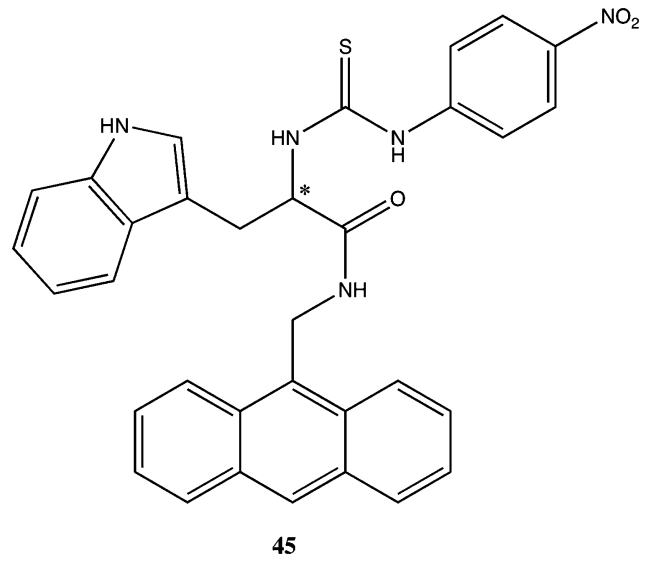

\section{Cation sensors}

\section{Examples of sensors for $\mathrm{H}^{+}$and group I and II alkali cations}

The sensing of protons still remains an active area of research due to the important role that $\mathrm{H}^{+}$play in cellular function as well as in many other biological processes. Typically, protons are recognised using amine based receptors, and hence it is 
common to find detailed descriptions of $\mathrm{pH}$-effects in studies of sensors desighedrtigle Online group I and II alkali cations; these often consist of crown ethers (of various sizes) or phenyl iminodiacetate based receptors. An example is 46, developed by Gunnlaugsson et al. ${ }^{32}$ originally as a $\mathrm{Zn}$ (II) sensor, but this sensor has also been shown to function as a fluorescent imaging agent by binding to $\mathrm{Ca}$ (II) in exposed bone structures (microcracks). However, due to the presence of the aniline moiety in 46, the fluorescence emission of the naphthalimide fluorophore was also shown to be $\mathrm{pH}$ sensitive, being 'switched on' upon protonation of the aniline moiety, as the oxidation potential of the receptor is affected, which prevents photoinduced electron transfer (PET) from the receptor to the naphthalimide excited state.

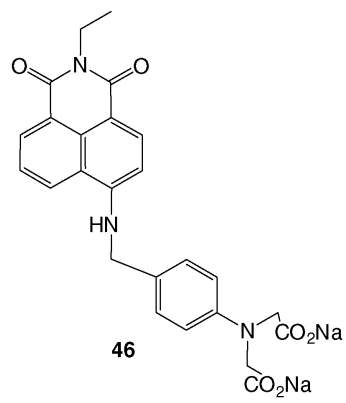<smiles>O=C1C=CC(=c2ccc3c(c2)Oc2cc(O)ccc2C=3c2ccccc2C(=O)O)C=C1</smiles>

An example of a selective $\mathrm{pH}$ sensor recently synthesised and investigated by Bradley et al..$^{33}$ is $\mathbf{4 7}$, based on the use of anthrofluorescein. The emission from this sensor was shown to be highly $\mathrm{pH}$ sensitive between $\mathrm{pH} 7-11$, where the emission spectrum was red shifted from green to red, due to the protonation of the phenolic position. The authors used this type of sensor for imaging the $\mathrm{pH}$ in cells, by simply diacetylating structure $\mathbf{4 7}$, which act at both facilitating the transport of the sensor across the cell membrane as well as enabling the imaging within the cellular environment.
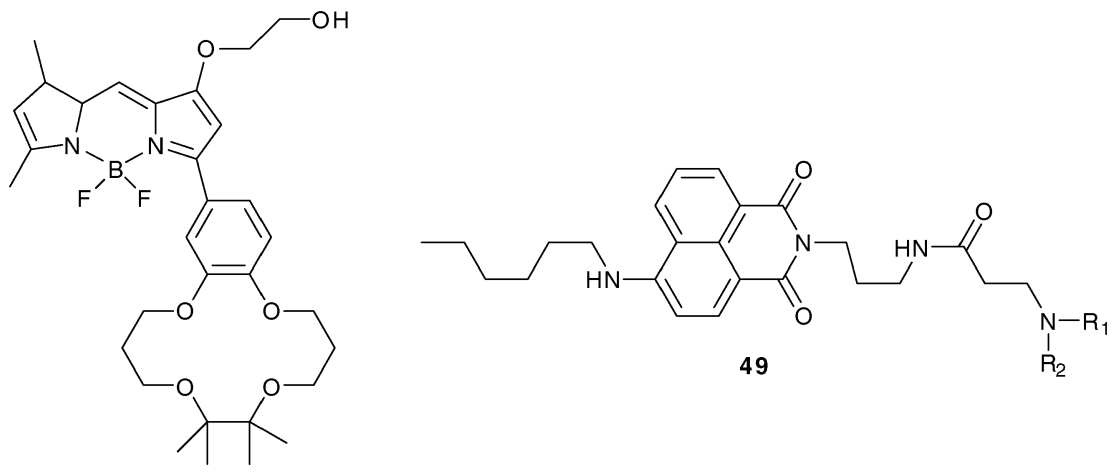

48

The sensing of the smallest group I alkali earth metal ion, lithium, has recently emerged as an active area of research. Unlike $\mathrm{Na}^{+}$and $\mathrm{K}^{+}, \mathrm{Li}^{+}$does not have a function in physiology, but is administrated as a drug for mental disorders, and has a rather low lethal dose. Consequently, there is growing interest in the development of 
sensors for $\mathrm{Li}^{+},{ }^{34}$ but due to its small size and high charge density, it is dilfficaltitié Online achieve such sensing in aqueous media. An example of such a sensor is $\mathbf{4 8}$, developed for the determination of free $\mathrm{Li}^{+}$in blood and serum samples. The sensor showed good selectivity for $\mathrm{Li}^{+}$over other competitive ions, but still the changes in the fluorescence emission spectrum were minor. Nevertheless, the presence of the free hydroxyl group in $\mathbf{4 8}$ facilitated the incorporation of this sensor onto porous silica glass support.

Chovelon et al. ${ }^{35}$ have also developed a sensor system for the selective colorimetric and fluorescent sensing of $\mathrm{Li}^{+}$, by incorporating sixteen 4-hexyl-1,8-naphthalimide units such as $\mathbf{4 9}$, into a polyamidoamine dendrimer. The sensing was achieved in DMF solution under alkaline conditions, where significant fluorescence enhancements were observed. However, it was found necessary to deprotonate the 4-amino moiety on the naphthalimide ring prior to the addition of $\mathrm{Li}^{+}$. However, some changes were also seen in the emission spectrum of $\mathbf{4 9}$ for ions such as $\mathrm{Na}^{+}$and $\mathrm{K}^{+}$.

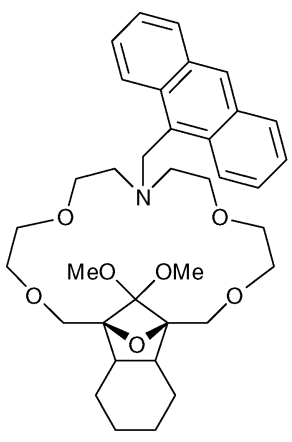

50

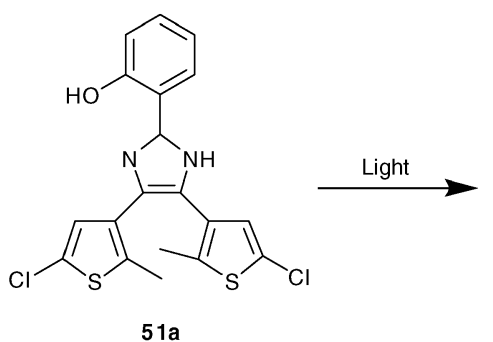

51a

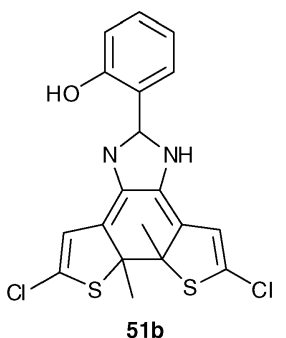

51b

The sensing of $\mathrm{Na}^{+}$and $\mathrm{K}^{+}$still remains an active area of research, and Khan et al. $^{36}$ developed $\mathbf{5 0}$ for such purposes. However, this sensor also showed good selectivity for ions such as $\mathrm{Zn}(\mathrm{II}), \mathrm{Ag}(\mathrm{I})$, and $\mathrm{Hg}$ (II) in organic solution where the anthracene emission was enhanced. While only small changes were observed in the emission upon binding to $\mathrm{Na}^{+}$, the crystal structure of the $\mathrm{Na}^{+}$complex of $\mathbf{5 0}$ was also presented and demonstrated that the ion coordinated not to the expected amino moiety but instead to the ether group. This binding preference is most likely the reason for the low enhancement in the emission of $\mathbf{5 0}$ upon binding of $\mathrm{Na}^{+}$, as the oxidation potential of the receptor is not significantly increased to block PET, enabling an active PET to occur, even in the presence of $\mathrm{Na}^{+}$.

Chen et al. have also recently developed $\mathbf{5 1}$ as a colorimetric and fluorescent sensor that can respond to group I metal ions with changes in the absorption spectrum, while changes in the emission spectrum were observed upon binding to $\mathrm{Cu}(\mathrm{II}){ }^{37}$ This selectivity depended on the structural form of 51, where 51a (the open form) was able to bind $\mathrm{Cu}$ (II) with quite a good selectivity, whereupon the emission was 'switched off', while a blue shift was observed for $\mathbf{5 1 b}$ (the closed form, formed by irradiation of 51a at $445 \mathrm{~nm}$ ) in the presence of either $\mathrm{Na}^{+}$or $\mathrm{K}^{+}$in $\mathrm{CH}_{3} \mathrm{CN}$.

Callan et al. have recently developed the tripodal fluorescent probe $\mathbf{5 2}$ for the detection of $\mathrm{Na}^{+}$and $\mathrm{K}^{+}$in a buffered mixture of $\mathrm{THF} / \mathrm{H}_{2} \mathrm{O}$ at $\mathrm{pH} 7{ }^{38}$ The sensor showed significant changes in the presence of $\mathrm{Na}^{+}$, which lead to preorganisation of the receptor moiety, enabling the binding of $\mathrm{K}^{+}$. This elegant example was used to demonstrate two-input AND molecular logic behaviour by the authors. 
<smiles>Cc1c(CSc2ccccc2N=Cc2c(O)ccc3ccccc23)c(C)c(CSc2ccccc2N=Cc2c(O)ccc3ccccc23)c(C)c1CSc1ccccc1N=Cc1c(O)ccc2ccccc12</smiles>

52

They showed that only in the presence of $\mathrm{Na}^{+}$, was the emission of $\mathbf{5 2}$ enhanced as stated above. But, upon the addition of $\mathrm{K}^{+}$the emission was red shifted, giving rise to the formation of a broad emission band. No such changes were, however, observed in the presence of $\mathrm{K}^{+}$alone.

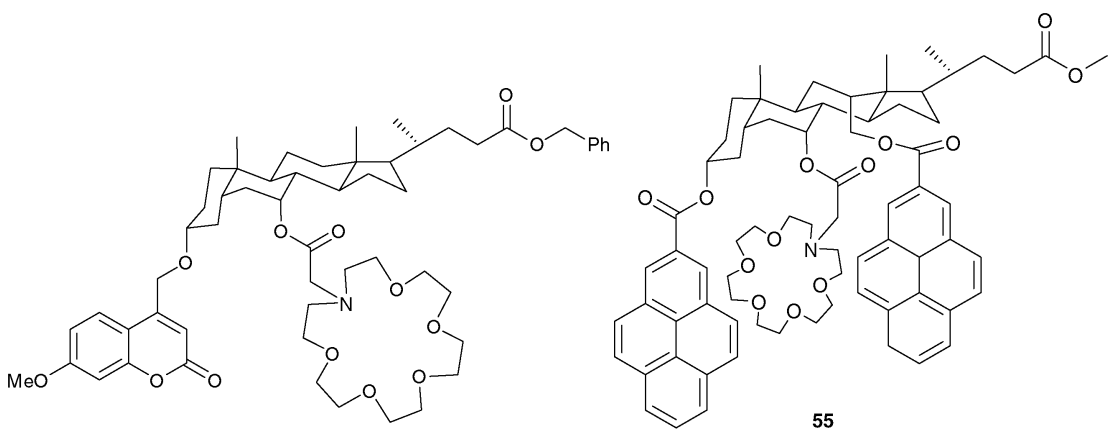

54

Maitra et al. have recently developed several bile acid derived PET sensors for the sensing of group I metal cations, using both pyrene and coumarine as fluorophores and a crown ether as a receptor. ${ }^{39}$ An example of these sensors is 53, where a single pyrene was incorporated into the sensor structure, but other analogues possessing two such fluorophores were also made (see $\mathbf{5 5}$ below). This sensor was shown to have good selectivity for $\mathrm{K}^{+}$over $\mathrm{Na}^{+}$in $\mathrm{MeOH}$, where the pyrene emission was enhanced upon binding of the cation. Using a smaller 15-crown-5 ether analogue also enabled the sensing of $\mathrm{Na}^{+}$, but surprisingly $\mathbf{5 3}$ was found to bind $\mathrm{Ba}$ (II) more strongly in the same medium. The same trend was also seen for the sensor $\mathbf{5 4}$, where the emission was enhanced in the presence of both $\mathrm{K}^{+}$and $\mathrm{Ba}(\mathrm{II})$ to a greater extent than for binding to $\mathrm{Na}^{+}$. The formation of the bis-pyrene system 9 was also undertaken with the view of improving the selectivity of the sensing, and also to enable fluorescence sensing via an excimer formation, or for monomer-excimer radiometric sensing. This was partially achieved, as $\mathbf{5 5}$ was shown to be a better sensor for $\mathrm{K}^{+}$than for $\mathrm{Ba}(\mathrm{II})$, where both the pyrene monomer and the excimer emissions were affected upon binding to the ion.

The development of sensors of group II ions remains an import area of research, as demonstrated by previous examples, and Vicens et al. developed $\mathbf{5 6}$ with the view of achieving high selectivity for $\mathrm{Mg}(\mathrm{II}) .{ }^{40}$ Similar to that shown above, this sensor 

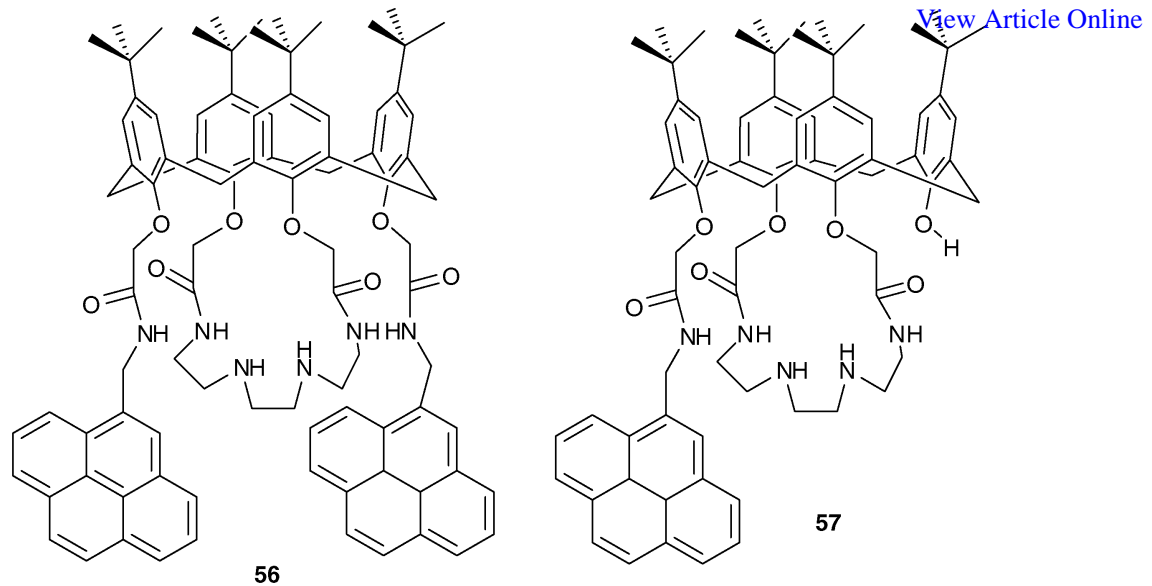

possesses two pyrene moieties, which sandwich a crown ether moiety, using a calix[4]arene as the platform for the incorporation of these structures. A second example, 57, possesses a single pyrene moiety and as for 53, above, only a monomeric emission was observed from this sensor. Upon titration of 57 with various group I and II metal ions, as well as d-metal ions, only $\mathrm{Mg}$ (II) gave rise to significant changes in the emission spectrum in $\mathrm{CH}_{3} \mathrm{CN}$ solution. Here, the monomer emission was enhanced at the expense of the excimer emission enabling ratiomeric sensing of this ion.

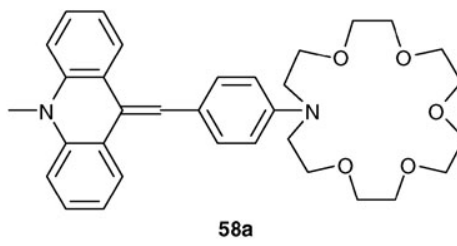

$58 \mathrm{a}$<smiles>CCOC(=O)CN(CC(=O)OCC)c1c([N+](=O)[O-])c(=O)oc2ccccc12</smiles>

59

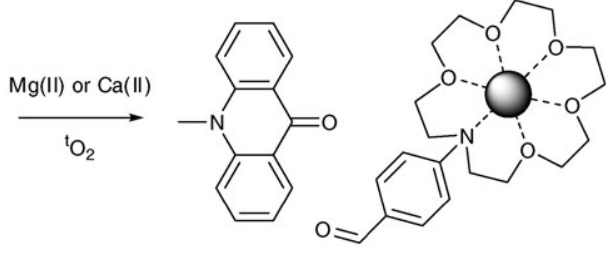

$58 b$

The recognition of $\mathrm{Mg}$ (II) and $\mathrm{Ca}$ (II) was also demonstrated by Motoyoshiya et al. ${ }^{41}$ using the chemiluminescence of benzylideneacridan molecule 58a, which was functionalised with a monoaza-15-crown-5 moiety. Strictly speaking, this is not a sensor element, as the recognition process is irreversible. Nevertheless, this system showed significant changes in its emission spectrum upon addition of $\mathrm{Ca}(\mathrm{II})$ or $\mathrm{Mg}$ (II) as perchloride salts in $\mathrm{CH}_{3} \mathrm{CN}$. The changes include the formation of chemiluminescence arising from the cleavage of 58a to give the species $\mathbf{5 8 b}$. The coumarin structure was also used by Das et al. ${ }^{42}$ for sensing of $\mathrm{Mg}$ (II) and Ca(II) in $\mathrm{CH}_{3} \mathrm{CN}$; the emission of 59 was enhanced by $c a .70$ and $50 \%$, for these ions, respectively, but some degree of quenching was also observed for the d-metal ions $\mathrm{Hg}(\mathrm{II}), \mathrm{Ni}(\mathrm{II}), \mathrm{Fe}(\mathrm{III})$ and $\mathrm{Co}(\mathrm{II})$. 
<smiles>COc1cc(C2C3=C(CC(C)(C)CC3=O)NC3=C2C(=O)CC(C)(C)C3)ccc1OCCOCCOCCOCCOc1ccc(C2C3=C(CC(C)(C)CC3=O)NC3=C2C(=O)CC(C)(C)C3)cc1OC</smiles>

60

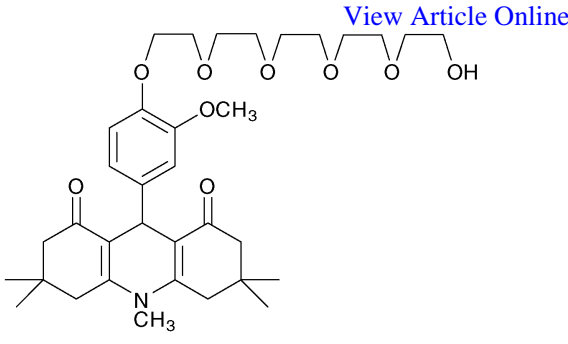

61

Similarly, Ramamurthy et al $^{43}$ developed $\mathbf{6 0}$ and $\mathbf{6 1}$ for the sensing of Ca(II) in $\mathrm{CH}_{3} \mathrm{CN}$. These acridinedione based systems were shown to bind perfectly $\mathrm{Ca}$ (II) in the presence of other biologically competitive group I and II ions, whereupon the emission of $\mathbf{6 0}$ was enhanced by a factor of two, and no visible changes were seen for $\mathrm{Mg}(\mathrm{II})$. The binding was also monitored by carrying out NMR titrations. Furthermore, the reversibility of the binding event was monitored in the emission spectrum by carrying out a back titration using EDTA. Similarly, 61 also bound Ca(II) preferentially over $\mathrm{Mg}$ (II), which gave rise to $c a$. $15 \%$ enhancement in the emission spectrum of $\mathbf{6 1}$. For both systems the mechanism for the changes in the emission spectrum were assigned to suppression via a PET from the receptor (i.e. the polyethoxy bridge connected to the $o$-methoxybenzene) to the acridinedione excited state.

\section{Examples of sensors for d-metal cations}

Many excellent examples of colorimetric or fluorescent sensors for d-metal ions were published in 2009, where the main focus was on the development of sensors for detecting either biologically active cations or those that are harmful to humans.<smiles></smiles>

62<smiles>O=[N+]([O-])c1ccc(NCCSCCCSCCNc2ccc([N+](=O)[O-])c3nonc23)c2nonc12</smiles>

63

An example of the latter is $\mathrm{Hg}$ (II), which is found in high abundance in nature as well as being the second most toxic metal ion. An example of a sensor for the detection of $\mathrm{Hg}$ (II) is that of Ihmels and Tian, ${ }^{44}$ who made the acridizinium based sensor 62, possessing a 1,4-dioxa-7,13-dithia-10-azacyclopendadecane based crown ether. In water, this sensor showed very good selectivity and sensitivity over other d-metal ions as well as groups I and II metal ions, where the emission was dramatically affected. Here, the long wavelength charge transfer band centred at ca. $540 \mathrm{~nm}$ reduced in intensity with the formation of a minor shorter wavelength band cantered at $c a .450 \mathrm{~nm}$ upon binding to $\mathrm{Hg}$ (II). This enabled the authors to analyse the binding of $\mathrm{Hg}$ (II) to $\mathbf{6 2}$ using ratiometric analysis of these two 
wavelengths. These changes were also accompanied by significant changeswifrtifie Online UV-Vis spectrum that could also be analysed in an analogous manner.

The structure $\mathbf{6 3}$ was developed by Grudpan et al. ${ }^{45}$ This sensor was found to bind highly selectively to $\mathrm{Hg}$ (II) in $\mathrm{CH}_{3} \mathrm{CN}$, as well as in mixed $\mathrm{CH}_{3} \mathrm{CN}$ water solution, where the emission was quenched in the presence of the ion, even at very low concentration, through the binding of the ion via a coordination to the dithioether spacer and the aryl amines.

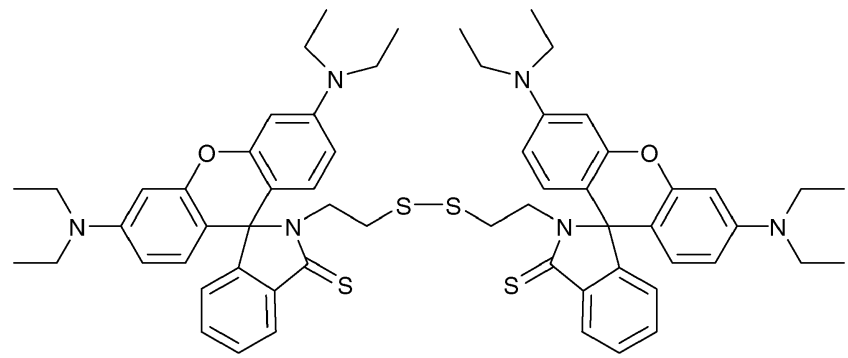

64<smiles>[Y2]CN(C)c1ccc2c(-c3ccccc3C3=NCCS3)c3ccc(=[N+](CC)CC)cc-3oc2c1</smiles>

65

The use of dithiolane lined chromophores as fluorescent probes for $\mathrm{Hg}$ (II) has also been demonstrated by Wang et al. ${ }^{46}$ who synthesized 64, possessing two thiorhodamine units. This system is best described as a chemodosimeter for $\mathrm{Hg}(\mathrm{II})$, as the recognition process gave rise to the ring opening of the thiorhodamine spirolactam to the corresponding thiazoline-derived open form $\mathbf{6 5}$ in real time (upon interacting with $\mathrm{Hg}(\mathrm{II})$, which induced desulfurization in $80: 20$ ethanol water mixture, whereupon the emission of $\mathbf{6 5}$ appeared. This probe was employed for imaging intracellular concentrations of $\mathrm{Hg}$ (II) using $\mathrm{HK}-2$ cells that were incubated with the probe at low concentration prior to treatment with increasing concentrations of $\mathrm{Hg}(\mathrm{II})$, where it was shown that the emission arising from the probe, increased as a function of increasing $\mathrm{Hg}$ (II) concentrations, enabling the imaging of the cells.<smiles>CCN(CC)c1ccc2c(-c3ccccc3C3=NCCO3)c3ccc(=[N+](CC)CC)cc-3oc2c1</smiles>

66<smiles>CC1=CC(C)=[N+]2B(F)n3c(C)cc(C)c3C(c3ccc(O)c(NCc4ccccn4)c3)=C12</smiles>

67 


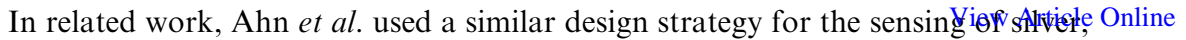
by using $\operatorname{Ag}(\mathrm{I})$ mediated spirolactam ring opening to give $66 .{ }^{47}$ Unlike $\mathbf{6 5}$, the product here was the oxazoline analogue and the authors were able to use silver nanoparticles to achieve this ring opening, demonstrating the use of this probe for detecting such nano-structures in solution. The use of other group II and d-metal ions did not give rise to such ring opening, demonstrating that the spirolactam sensor was highly selective for the detection of $\operatorname{Ag}(\mathrm{I})$, since the emission of the spirolactam was enhanced upon transformation into 66.

You et al. have recently developed the boron-dipyrromethane (BODIPY) based sensor 67 for sensing $\mathrm{Hg}$ (II) in $(1: 99 \mathrm{v} / \mathrm{v})$ DMSO-HEPES buffer mixture. ${ }^{48}$ The emission from 67, occurring in the visible region, was enhanced by several orders of magnitude upon binding to $\mathrm{Hg}$ (II), while other group II and d-metal ions did not give rise to any significant changes in the fluorescence emission spectrum. The sensitivity of this sensor was very good, with a detection limit reported to be as low as $2 \mathrm{ppb}$. The selectivity was also very good, as upon addition of the $\mathrm{Hg}$ (II) ion to solutions of 67 that contained $50 \mu \mathrm{M}$ concentrations of various d-metal ions, the emission was enhanced to the same level as seen upon addition of $\mathrm{Hg}$ (II) alone. As for 67, this sensor was successfully employed for cellular imaging using HeLa cancer cells.<smiles>CCCCOc1cc(-c2ccc(N=CC3=CC=C4C=CC5=CC=CC6=CC=C3C4C56)cc2)c(-c2ccc(N=CC3=CC=C4C=CC5=CC=CC6=CC=C3C4C56)cc2)cc1OCCCC</smiles><smiles>[R]C=Nc1ccc(-c2cc3c(cc2-c2ccc(N=CP)cc2)OCCOCCOCCOCCO3)cc1</smiles><smiles>CC1=CC2=CC=CC3=CC=CC(=C1)C32</smiles><smiles>Cc1ccc2ccccc2n1</smiles>

Bhalla et al. developed two examples, 68 and 69a,b as fluorescent sensors for $\mathrm{Hg}$ (II) based on the use of the terphenyl platform. ${ }^{49,50}$ Both 68 and 69a were based on the use of pyrene as a fluorophore, but a quinoline analogue 69b was also developed. ${ }^{50}$ The sensing of $\mathrm{Hg}(\mathrm{II})$ was achieved by 68 in a $9.5: 0.5(\mathrm{v} / \mathrm{v})$ mixture of THF and water, where the emission of $\mathbf{6 8}$ was enhanced by a factor of $c a$. five, while 
other transition metal ions, as well as group I metal ions, did not give riseuterdifife Online enhancement. The binding of $\mathrm{Hg}(\mathrm{II})$ to $\mathbf{6 8}$ was found to be in a $1: 1$ stoichiometry by using Job's plot analysis. Similarly, the sensing of 69a was investigated, and shown to give rise to a large enhancement in the monomeric pyrene emission. The quinoline analogue 69b also gave rise to such changes, which occurred with the addition of $1 \rightarrow 8 \mu \mathrm{M}$ concentration of $\mathrm{Hg}(\mathrm{II})$. The emission of this analogue was also red shifted in comparison to the pyrene emission. For both sensors 69a and $69 \mathrm{~b}$, the recognition was thought to occur via the binding of the metal ion at the crown ether moiety; as with other sensors highlighted here, only a minor emission enhancement was seen using other competitive group I and d-metal ions.

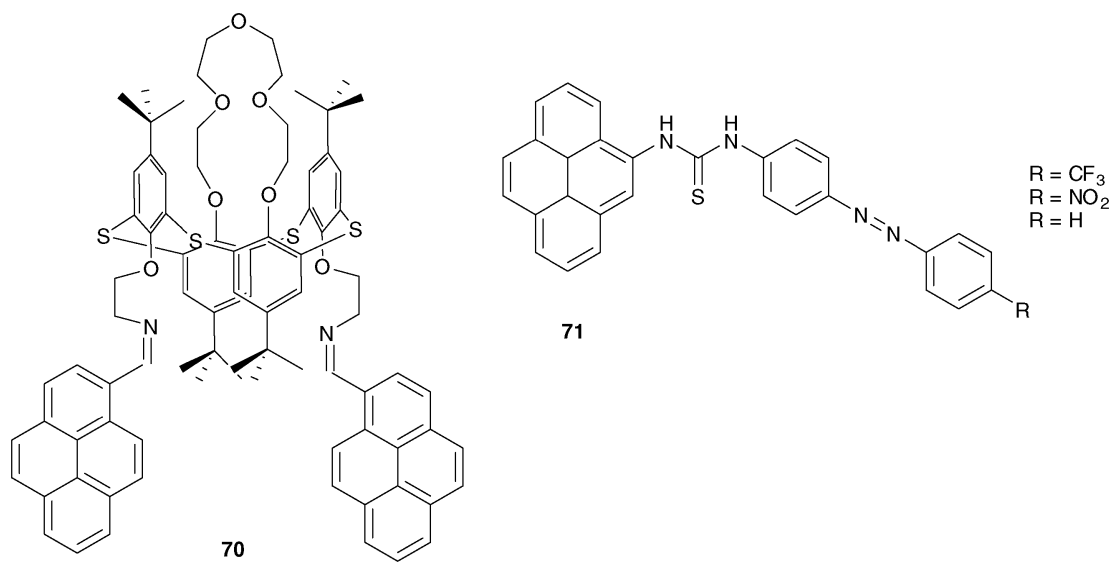

The use of pyrene imines has been further investigated by Mumar et al., who made 70, a thiacalix[4]arene based sensor for ions such as $\mathrm{Hg}$ (II), $\mathrm{Pb}$ (II) and $\mathrm{Cu}(\mathrm{II}){ }^{51}$ This system is highly preorganised, possessing a 'crown ether moiety' connected via the 1 , 3 positions of the thiacalix[4]arene, which maximise the orbital overlap between the two pyrene units, giving rise to strong excimer emission in the absence of the d-metal ions. However, the excimer as well as the monomer pyrene emission was shown to be effectively quenched in the presence of these ions in the aprotic mixture of $\mathrm{CH}_{3} \mathrm{CN}-\mathrm{CH}_{2} \mathrm{Cl}_{2}$.

Yen et al. ${ }^{52}$ have also used the pyrene fluorophore in the sensing of $\mathrm{Hg}$ (II). Several sensors of the general structure 71 (with $\mathrm{R}=\mathrm{CF}_{3}, \mathrm{NO}_{2}$ or $\mathrm{H}$ ) were synthesised, but these were all based on the use of an azobenzene unit (possessing the substituents $\mathrm{R}$ ) conjugated to the pyrene moiety via a thiourea spacer. The sensor showed minor changes in the absorption spectrum upon binding to $\mathrm{Hg}(\mathrm{II})$ within the $0 \rightarrow 30 \mu \mathrm{M}$ concentration of the ion; analysis of which showed that the binding occurred in a $1: 1$ stoichiometry in 9:1 DMSO:water solution. In contrast, large concomitant changes were observed in the fluorescence emission spectrum of 71 upon $\mathrm{Hg}$ (II) recognition; the emission was also clearly visible to the naked eye under light irradiation. The recognition process was thought to be due to conversion of the thiourea to the urea analogue, which is more emissive. Hence, the recognition process was an irreversible reaction between $\mathbf{7 1}$ and $\mathrm{Hg}$ (II). This was confirmed by synthesising the urea analogue of $\mathbf{7 1}$, which displayed the same ${ }^{1} \mathrm{H}$ NMR as that observed for sensor $\mathbf{7 1}$ after the treatment with $\mathrm{Hg}(\mathrm{II})$. 
<smiles>c1coc(CN(CCN(Cc2ccc3ccccc3n2)Cc2ccc3ccccc3n2)CCN(Cc2ccc3ccccc3n2)Cc2ccco2)c1</smiles><smiles>N#CC(C#N)=C1C(Cl)=C(N(Cc2ccccn2)Cc2ccccn2)c2cc(-c3cccc4cccnc34)ccc21</smiles>

73

Gosh et al. have also developed sensors for $\mathrm{Hg}(\mathrm{II}), \mathrm{Cu}(\mathrm{II})$ and $\mathrm{Zn}(\mathrm{II}) .{ }^{53}$ An example of these systems is $\mathbf{7 2}$ based on the use of a 'paddlewheel' concept where three quinoline fluorophores were introduced into a tren ligand. An analogous example, possessing three anthracene moieties was also developed. Upon binding of the above ions, significant enhancement was observed in the emission of 72, which displayed a broad emission band centred at $c a .430 \mathrm{~nm}$, being red shifted in comparison with the free sensor. The quinoline chromophore has also been used by Torroba et al. who developed 73 for the sensing of $\mathrm{Cu}(\mathrm{II})$ in a $1: 1$ mixture of $\mathrm{CH}_{3} \mathrm{CN}-\mathrm{H}_{2} \mathrm{O}$. ${ }^{54}$ The sensor showed significant changes in both the UV-Vis absorption and in the emission spectrum upon binding to $\mathrm{Cu}(\mathrm{II})$, in contrast to other d-metal ions. Using Job's plot analysis, the authors demonstrated the $1: 1$ binding of $\mathrm{Cu}$ (II) to 73 .<smiles>COCCOc1ccc(C(=O)Nc2cccc3ccccc23)cc1OCCOC</smiles><smiles>COCCOc1ccc(C(=O)Nc2cccc3ccccc23)cc1OCC1CC1</smiles><smiles>c1ccc2c(SCCOCCOCCSc3c[nH]c4ccccc34)c[nH]c2c1</smiles>

75

74

Goswami and Chakrabarty developed a fluorescent sensor for $\mathrm{Cu}(\mathrm{II})$, by using the pseudo 18-crown-6 structure 29. ${ }^{55}$ Job's plot analysis of 29 in $9: 1 \mathrm{CH}_{3} \mathrm{CN}-\mathrm{H}_{2} \mathrm{O}$ showed that the sensor bound several d-metal ions with $1: 1$ stoichiometry, of which $\mathrm{Cu}(\mathrm{II})$ was found to be bound the strongest. While minor changes were observed in the absorption spectrum of $\mathbf{2 9}$ upon binding to $\mathrm{Cu}(\mathrm{II})$, the emission was greatly affected, being red shifted, while other d-metal ions did not give rise to such spectral changes. The red shift was assigned to the formation of an excimer between the two naphthalene fluorophores, caused by conformational changes in the structure of 29 upon recognition of $\mathrm{Cu}(\mathrm{II})$. Similarly, the use of such "half-crown ether" or podants for the sensing of $\mathrm{Cu}$ (II) was also investigated by Lodeiro et al. ${ }^{56}$ who made sensor 30, possessing two indole fluorophores. In $\mathrm{CH}_{2} \mathrm{Cl}_{2}$, this sensor was able to detect $\mathrm{Cu}$ (II), $\mathrm{Cd}$ (II), $\mathrm{Hg}$ (II) and $\mathrm{Pb}$ (II), with $c a .10-20 \%$ reduction in the intensity of the emission spectrum, while the titration with $\mathrm{Ag}(\mathrm{I})$ gave rise to $c a .50 \%$ quenching. 
<smiles>Oc1ccc2ccccc2c1/C=N/CC1CCC2CC1C2</smiles>

76<smiles>Oc1ccc2ccccc2c1/C=N\c1ccccc1OCCOCCOc1ccccc1/N=C\c1c(O)ccc2ccccc12</smiles>

77

Callan et al. also developed a sensor the detection of $\mathrm{Ag}$ (I), as well as $\mathrm{Mn}$ (II), by developing a polymer based on the general structure $76 .{ }^{57}$ This poly-Schiff base based polymeric network was found to give colorimetric response for $\operatorname{Ag}(\mathrm{I})$ where the absorption spectrum of $\mathbf{7 6}$ was red shifted, while the emission spectrum was most affected upon titrating the polymer with $\mathrm{Mn}$ (II), being both slightly red shifted as well as enhanced. The use of Schiff base receptors for such d-metal ion sensing was also explored in examples $\mathbf{6 8 - 7 0}$ above, and also in 77, developed by Lodeiro et al. for the sensing of ions such as $\mathrm{Cu}(\mathrm{II}), \mathrm{Zn}$ (II), $\mathrm{Cd}(\mathrm{II})$ and $\mathrm{Hg}(\mathrm{II}),{ }^{58}$ which is structurally related to 76. This design gave rise to significant changes in both the absorption and the emission spectrum of 77 upon interactions with the aforementioned ions, where the emission was on all occasions quenched in DMSO solution. Of these ions, $\mathrm{Cu}$ (II) was found to be bound the strongest, with a binding constant $\log K=5.81$.<smiles></smiles>

78

The naphthalimide based sensor $\mathbf{7 8}$ was developed by Bojinov and Panova for the sensing of d-metal ions. ${ }^{59}$ In DMF solution an active PET occurred from the amine to the excited state of the naphthalimide, quenching the emission. However, upon titration with ions such as $\mathrm{Cu}(\mathrm{II})$, the PET was blocked, giving rise to three fold enhancement in the emission. Similarly, $\mathrm{Pb}$ (II), $\mathrm{Ni}$ (II) and $\mathrm{Zn}$ (II) also gave rise to an enhancement in the naphthalimide emission spectrum of $\mathbf{7 8}$, but to a lesser extent than that seen for $\mathrm{Cu}(\mathrm{II})$. Sensor 79 was developed by Lin et al. ${ }^{60}$ as a probe for ions such as $\mathrm{Co}$ (II) and $\mathrm{Ni}(\mathrm{II})$. In both cases, the fluorescence emission of $\mathbf{7 9}$ was enhanced 
by a factor of six, with a modest selectivity being observed for Ni(II) oveructortif), Online while minor enhancements were observed in the emission spectrum of 79 in the presence of other d-metal ions in methanol solution.<smiles>CCN(CC)c1ccc2cc(C(=O)NCc3ccccn3)c(=O)oc2c1</smiles>

The coumarin fluorophore has also been used for the sensing of $\mathrm{Cu}(\mathrm{II})$ by $\mathrm{Kim}$ et al. ${ }^{61}$ who made $\mathbf{8 0}$. A crystal structure of $\mathbf{8 0}$ with $\mathrm{Cu}$ (II) showed that the $\mathrm{Cu}(\mathrm{II})$ was coordinated to the pyridyl unit, the amide nitrogen and the oxygen of the carbonyl function of the coumarin ring. The binding of $\mathrm{Cu}$ (II) gave rise to minor changes in the absorption spectrum, but in contrast, the emission of $\mathbf{8 0}$ was almost fully quenched. The authors used this sensor for cellular imaging of $\mathrm{Cu}$ (II) in LLC-MK2 liver cells. Similarly, the coumarin sensor $\mathbf{8 1}$ was developed by Brückner et l. $^{62}$ as a chemidosimeter for $\mathrm{Fe}(\mathrm{III})$ ions, or other oxidants such as $\mathrm{Cr}(\mathrm{VI})$ or $\mathrm{Ce}(\mathrm{Iv})$, where the emission of $\mathbf{8 1}$ was greatly enhanced ( $c a .9$ fold) in buffered $\mathrm{pH} 4.4$ solution.
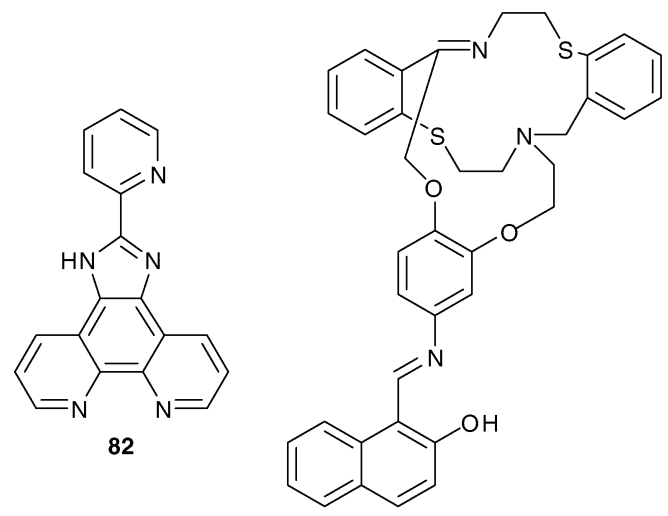

83

The sensing of $\mathrm{Co}(\mathrm{II})$ has also been achieved by Wang et al. ${ }^{63}$ using the phenantholine based fluorescent sensor 82. In DMF buffered solution, the phenantholine emission was quenched upon binding of $\mathrm{Co}$ (II). Analysis of the stoichiometry of this binding process showed that $\mathbf{8 2}$ bound Co(II) both at the phenantholine side, as well as at the imidazole side, where the second ion was bound through direct coordination to the imidazole nitrogen and the appended pyridyl unit. The reversibility of this binding was demonstrated by using EDTA, which upon extraction of the Co(II) reversed the changes in the emission spectrum of $\mathbf{8 2}$. Sensor 83 was also developed by Ocak et al. ${ }^{64}$ for the sensing of Co(II) in organic solvent mixture. Using the same naphthalene structure as used in sensors 75 and $\mathbf{7 6}$ above, significant changes were seen in the absorption spectrum of $\mathbf{8 3}$ upon binding to 
several d-metal ions, $\mathrm{Al}(\mathrm{III}), \mathrm{Sr}(\mathrm{II})$, etc. The emission spectrum of $\mathbf{8 3}$ was al\$dexffectiedt Online by these same ions, but the most dramatic changes were observed for Co(II) which gave rise to $84 \%$ quenching in the emission upon the addition of 0.5 equivalents of the ion. Analysis of these changes showed that the overall stoichiometry was $2: 1$ (L: M) indicating that the ion was sandwiched by two of these sensors, most likely involving the naphthalene imide moieties.
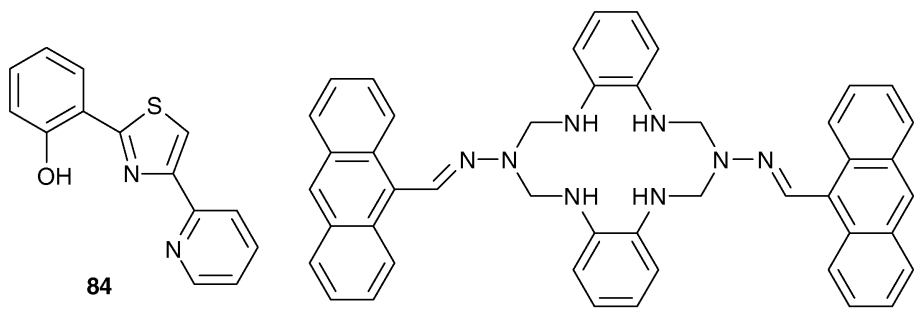

85

Interest in the sensing of $\mathrm{Zn}$ (II) ions continues to grow due to its significant role in various physiological processes and (being the second most abundant metal ion in the human body after iron) in cellular and enzymatic functions and due to its importance in various neurological disorders. Examples of $\mathrm{Zn}$ (II) sensors published in the 2009 literature include $\mathbf{8 4}$ and $\mathbf{8 5}$; where two very different structural designs were employed. Sensor $\mathbf{8 4}$ was developed by Helal and Kim, ${ }^{65}$ and is based on the use of phenole, thiazole and pyridine moieties within a single structure, where the binding of $\mathrm{Zn}$ (II) causes inhibition of intramolecular proton transfer within the excited state of the sensor. This inhibition gives rise to significant changes in both the absorption spectrum of $\mathbf{8 4}$, with the formation of a long wavelength absorption band, as well as in the emission spectrum, which was both blue shifted and enhanced by $c a$. factor of 2 , with the addition of $0 \rightarrow 0.6$ equivalents of $\mathrm{Zn}$ (II). However, upon further addition, the emission was quenched again, by $c a$. $20 \%$. The structure 85 was developed by Chen et al. ${ }^{66}$ who demonstrated the sensing of $\mathrm{Zn}$ (II) in a $8: 2$ $\mathrm{MeOH}: \mathrm{H}_{2} \mathrm{O}$ solution. The sensing of $\mathrm{Zn}$ (II) gave rise to changes in both the $\mathrm{UV}-\mathrm{Vis}$ and the fluorescence emission spectrum of sensor 85. The addition of $0 \rightarrow 1$ equivalents of $\mathrm{Zn}$ (II) caused the absorption band of the anthracene moiety to be red shifted, and the emission, cantered at $c a .446 \mathrm{~nm}$, was enhanced by several orders of magnitudes. Using Job's plot analysis, the authors showed that the metal ion was bound in a $1: 1$ stoichiometry, and the sensing of $\mathrm{Zn}$ (II) in the presence of various group I, II and transition metal ions was possible, as only minor changes were observed for these competitive ions.

Sensors $\mathbf{8 6}{ }^{67}$ and $\mathbf{8 7 ^ { 6 8 }}$ were developed by Lippard et al. for the sensing of $\mathrm{Zn}$ (II), but the Lippard research group has been at the forefront of this field of research for many years. The two sensors differ in the nature of the pyridyl receptor groups (the location of the nitrogen atom i.e. 2-pyridyl vs. 4-pyridyl for two of the four pyridyl units employed in these structures) and the structure of the fluorophore, which in the case of 86, is based on the use of di-fluoride substituted fluorescein, while $\mathbf{8 7}$ is based on the use of di-chloro fluorescein. The authors showed that these systems are very good sensors for $\mathrm{Zn}$ (II); though the structural modification on the receptor part of $\mathbf{8 6}$ does reduce the affinity of this sensor for $\mathrm{Zn}$ (II) over that seen for $\mathbf{8 7}$. These structural modifications were also carried out with the view of lowering the $\mathrm{pH}$ sensitivity of 


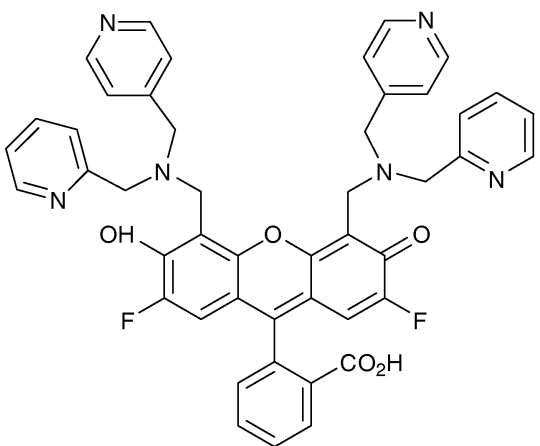

86

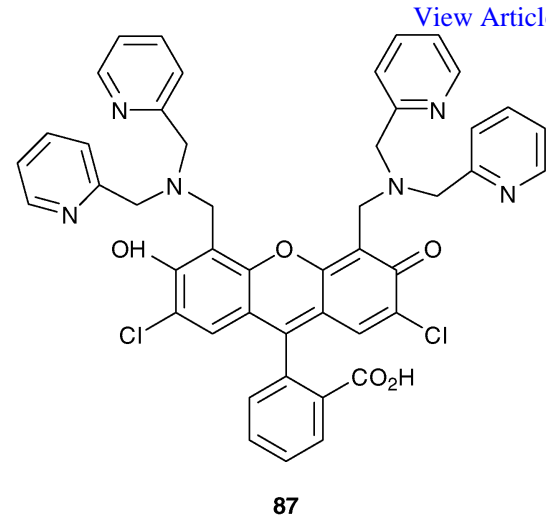

87

these sensors, which can give rise to a false-positive response in such sensors, particularly when used in vivo. The authors showed that these modifications only gave rise to relatively small changes in the $\mathrm{p} K_{\mathrm{a}}$ values for the two sensors, and that for both sensors, significant enhancements were seen in their emission spectrum upon binding of $\mathrm{Zn}(\mathrm{II})$. Sensor $\mathbf{8 6}$ was also used for imaging cells using confocal fluorescence microscopy and shown to successfully bind $\mathrm{Zn}$ (II) within these cells. Using sensor 87, the authors carried out a comprehensive binding studies on the sensor, and other structurally related ones and demonstrated, using both potentiometric titrations and X-ray crystallography, that the pyridyl units were involved in the sensing, and that the hydroxyl group of the fluorophore could also participate in the binding of the $\mathrm{Zn}$ (II) ion.

The naphthalimide based dendrimer sensor $\mathbf{8 8}$ was developed by Staneva et al. ${ }^{69}$ This sensor gives rise to a broad emission band at long wavelength similar to that seen for $\mathbf{8 6}$ and 87. The sensor was shown to have good affinity for $\mathrm{Zn}$ (II) when measured in DMF solution, which was significantly enhanced after the deprotonation of the sensor using $\mathrm{NaOH}$. The sensor was also shown to bind other d-metal cations such as $\mathrm{Pb}(\mathrm{II}), \mathrm{Cu}(\mathrm{II}), \mathrm{Co}(\mathrm{II})$ and $\mathrm{Fe}(\mathrm{III})$. The changes in the absorption spectrum were also monitored in the presence of $\mathrm{NaOH}$ where the ICT band of the naphthalimide fluorophore was red shifted, indicating the deprotonation event. Hence, this sensor can be described as a dual sensor for both cations and anions, as other anions can also induce such deprotonation in organic solution as discussed earlier in the chapter.

The development of sensors for both cations and anions (di-topic), or sensors that can give rise to significant enhancement in the sensing of cations after a protonation event (e.g. as last example illustrated) is a growing field. The final example discussed in this chapter, that of Chung et al., ${ }^{70}$ is based on a calix[4]arene possessing two naphthalene based fluorophores. The sensor 89 was characterised using X-ray crystal structure analysis and the sensing ability of this structure was evaluated in $\mathrm{CH}_{3} \mathrm{CN}$ solution. Using a range of group I and II as well as d-metal ions, the authors demonstrated that $\mathrm{Ag}(\mathrm{I}), \mathrm{K}^{+}$and $\mathrm{Li}^{+}$all gave rise to small enhancement in the emission spectrum of $\mathbf{8 9}$, while $\mathrm{Cu}$ (II) gave rise to significant quenching of the naphthalene emission. A formation of a Metal-to-Ligand Charge Transfer MLCT band was also observed in the absorption spectrum of the sensor demonstrating the binding of $\mathrm{Cu}(\mathrm{II})$. The authors also showed that the binding of $\mathrm{Cu}(\mathrm{II})$ was in a $1: 1$ stoichiometry, and that the counter ion (various anions) could have a significant affect on the emission intensity. Hence, addition of either fluoride or acetate gave rise 

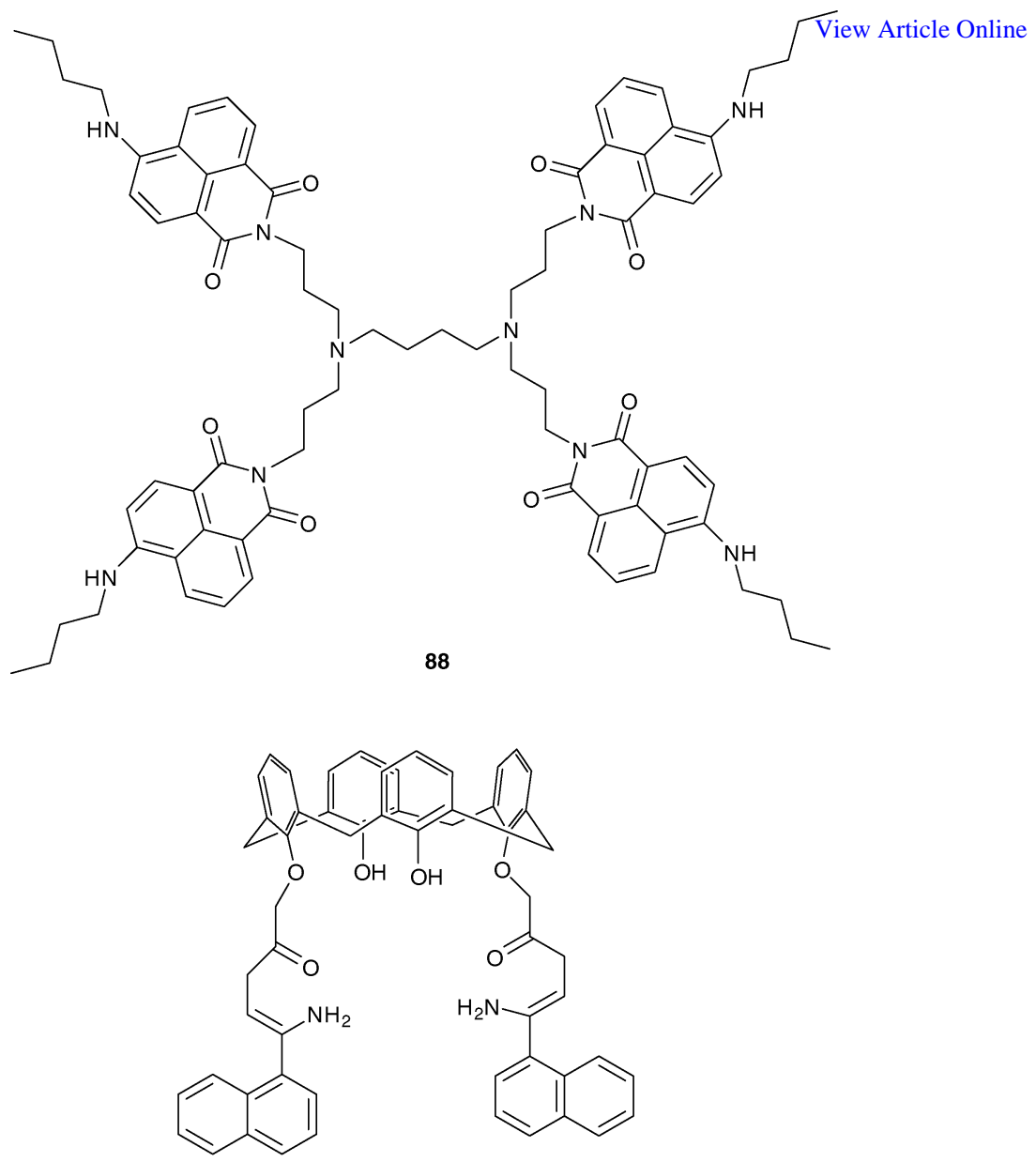

89

to additional enhancements and changes in the colour of the solution, which were clearly visible to the naked eye.

\section{Conclusion}

In this section we have highlighted some of the examples of fluorescent (and colorimetric) anion sensors published in 2009. This area of research is highly topical and fast growing within the area of organic supramolecular chemistry. The examples shown above, demonstrate the broad scope of this field and its potential future within supramolecular chemistry.

\section{Conclusion}

In this chapter we have tried to give an overview of some of the examples of organic structures developed for use as fluorescent anion and cation sensors in the 2009 literature. As stated at the beginning of this chapter, this is both a very active and fast growing field of research, which overlaps with the area of organic supramolecular chemistry, and consequently it is impossible to discuss all the 
examples released in 2009. Nevertheless, we hope that our choice of Viexumplifele Online demonstrates the activity in the field and the important role that organic synthetic chemistry plays in the construction of such systems.

\section{References}

1 J. Shao, X. Yu, X. Xu, H. Lin, Z. Cai and H. Lin, Talanta, 2009, 79, 547.

2 J. Shao, Y. Qiao, H. Lin and H. Lin, J. Fluoresc., 2009, 19, 183.

3 J. Shao, H. Lin, Z.-S. Cai and H. Lin, J. Photochem. Photobiol., B, 2009, 95, 1.

4 (a) Y. Sun, Y. Liu, M. Chen and Q. Guo, Talanta, 2009, 80, 996; (b) Y. Sun, Y. Liu and W. Guo, Sens. Actuators, B, 2009, 143, 171.

5 S.-Y. Chung, S.-W. Nam, J. Lim, S. Park and J. Yoon, Chem Commun., 2009, 2866.

6 Y. Shiraishi, H. Maehara and T. Hirai, Org. Biomol. Chem., 2009, 7, 2072.

7 R. Pérez-Riuz, Y. Díaz, B. Goldfuss, D. Hertel, K. Meerholz and A. G. Griesbeck, Org. Biomol. Chem., 2009, 7, 3499.

8 X. Bao, J. Yu and Y. Zhou, Sens. Actuators, B, 2009, 140, 467.

9 S. V. Bhosale, S. V. Bhosale, M. B. Kalyankar and S. J. Langford, Org. Lett., 2009, 11, 5418.

10 E. B. Veale, G. M. Tocci, F. M. Pfeffer, P. E. Kruger and T. Gunnlaugsson, Org. Biomol. Chem., 2009, 7, 3447.

11 R. Ferreira, P. Remón and U. Pischel, J. Phys. Chem. C, 2009, 113, 5805.

12 Y. Qu, J. Hua, Y. Jiang and H. Tian, J Polym. Sci.,: Part A: Polym Chem, 2009, 47, 1544.

13 P. Zhao, J. Jiang, B. Leng and H. Tian, Macromol. Rapid Commun., 2009, 30, 1715.

14 N. Singh, N. Kaur, J. Dunn, R. Behan, R. C. Mulrooney and J. F. Callan, Eur. Poly. J., 2009, 45, 272.

15 M. Teng, G. Kuang, X. Jia, M. Gao, Y. Li and Y. Wei, J. Mater. Chem., 2009, 19, 5648.

16 Z. Xu, S. K. Kim, S. J. Han, C. Lee, G. Kociok-Kohn, T. D. James and J. Yoon, Eur. J. Org. Chem., 2009, 18, 3058.

17 Q.-S. Lu, L. Dong, J. Zhang, J. Li, L. Jiang, Y. Huang, S. Qin, C.-W. Hu and X.-Q. Yu, Org. Lett., 2009, 11, 669.

18 Y.-C. Lin and C.-T. Chen, Org. Lett., 2009, 11, 4858.

19 J. R. Hiscock, C. Caltagirone, M. E. Light, M. B. Hursthouse and P. A. Gale, Org. Biomol. Chem., 2009, 7, 1781.

20 S. Goswami, A. Haxara, R. Chakrabarty and H.-K. Fun, Org. Lett., 2009, 11, 4350.

21 G. W. Lee, N. Singh, H. J. Jung and D. O. Jang, Tetrahedron Lett., 2009, 50, 807.

22 K. Ghosh and A. R. Sarkar, Tetrahedron Lett., 2009, 50, 85.

23 Y. Sun, C. Zhong, R. Gong, H. Mu and E. Fu, J. Org. Chem., 2009, 74, 7943.

24 K.-H. Chen, J.-H. Liao, H.-Y. Chan and J.-M. Fang, J. Org. Chem., 2009, 74, 895.

25 H. S. Jung, H. J. Kim, J. Vicens and J. S. Kim, Tetrahedron Lett., 2009, 50, 983.

26 Y. Liu, Z. Li and D.-S. Guo, Supramol. Chem., 2009, 21, 465.

27 C. G. Hu, X. H. Huang, Z. H. Chen and Y. B. He, Chin. J Chem., 2009, 27, 157.

28 K.-X. Xu, Z. Qiu, J.-J. Zhao, J. Zhao and C.-J. Wang, Tetrahedron: Asymmetry, 2009, 20, 1690.

29 F. Han, L. Chi, X. Liang, S. Ji, S. Liu, F. Zhou, Y. Wu, K. Han, J. Zhao and T. D. James, J. Org. Chem., 2009, 74, 1333.

30 A. Sirikulkajorn, P. Duanglaor, V. Ruangpornvisuti, B. Tomapatanaget and T. Tuntulani, Supramol. Chem., 2009, 21, 486.

31 X.-H. Huang, Y.-B. He, C.-G. Hy and Z.-H. Chen, J. Fluoresc., 2009, 19, 97.

32 R. Parkesh, T. Clive Lee and T. Gunnlaugsson, Tetrahedron Lett., 2009, 50, 4114.

33 A. Unciti-Broceta, M. R. Yusop, P. R. Richardson, J. G. A. Walton and M. Bradley, Tetrahedron Lett., 2009, 50, 3713.

34 S. Rochat, Z. Grote and K. Severin, Org. Biomol. Chem., 2009, 7, 1147; Y. Ando, Y. Hiruta, D. Citterio and K. Suzuki, Analyst, 2009, 134, 2314.

35 I. Grabchev, S. Dumas and J. M. Chovelon, Dyes and Pigments, 2009, 82, 336.

36 F. A. Khan, K. Parasurman and K. K. Sadhu, Chem. Commun., 2009, 2399.

37 H.-h. Liu and Y. Chen, Eur. J. Org. Chem., 2009, 5261.

38 N. Kaur, N. Singh, D. Cairns and J. F. Callan, Org. Lett., 2009, 11, 2229.

39 U. Maitra and S. Nath, Chem. Asian J., 2009, 4, 989.

40 A. Hamdi, S. H. Kim, R. Abidi, P. Thuery, J. s. Kim and J. Vicens, Tetrahedron, 2009, 65, 2818.

41 J. Motoyoshiya, T. Tanaka, M. Kuroe and Y. Nishii, J. Org. Chem., 2009, 74, 1014.

42 M. Suresh and A. Das, Tetrahedron Lett., 2009, 50, 5808. 
43 P. Ashokkumar, V. T. Ramakrishnan and P. Ramamurthy, Eur. J. Org. CKkerw., Azrogeg, Online 5941.

44 M. Tian and H. Ihmels, Chem. Commun., 2009, 3175.

45 N. Wanichacheva, M. Siriprumpoonthum, A. Kamkaew and K. Grudpan, Tetrahedron Lett., 2009, 50, 1783.

46 W. Liu, L. Xu, H. Zhang, J. You, X. Zhang, R. Shen, H. Li, S. Wu and P. Wang, Org. Biomol. Chem., 2009, 7, 660.

47 A. Chatterjee, M. Santra, N. Won, S. Kim, J. K. Kim, S. B. Kim and K. H. Ahn, J. Am. Chem. Soc., 2009, 131, 2040.

48 Lu, L. Xiong, H. Liu, M. Yu, Z. Shen, F. Li and X. You, Org. Biomol. Chem., 2009, 7, 2554.

49 V. Bhalla, R. Tejpal, M. Kumar, R. K. Puri and P. K. Mahajan, Tetrahedron Lett., 2009, 50, 2649.

50 V. Bhalla, R. Tejpal, M. Kumar and A. Sethi, Inorg. Chem., 2009, 48, 11677.

51 M. Kumar, A. Dhir and V. Bhalla, Eur. J. Org. Chem., 2009, 4534.

52 C.-C. Chen, Z.-S. Chen, C.-Y. Wu, C.-C. Lin, C.-R. Yan and Y.-P. Yen, Sensor and Actuators B, 2009, 142, 280.

53 B. N. Ahamed, I. Ravikumar and P. Gosh, New J. Chem., 2009, 33, 1825.

54 E. Ballesteros, D. Moreno, T. Gómez, T. Rodríguez, J. Roja, M. García-Valverde and T. Torraba, Org. Lett., 2009, 11, 1269.

55 S. Goswami and R. Chakrabarty, Tetrahedron Lett., 2009, 50, 5910.

56 A. Rocha, M. M. B. Marques and C. Lodeiro, Tetrahedron Lett., 2009, 50, 4930.

57 N. Singh, N. Kaur, C. N. Choitir and J. F. Callan, Tetrahedron Lett., 2009, 50, 4201.

58 L. Fernandes, M. Boucher, J. Fernandez-Lodeiro, E. Oliveira, C. Nunez, H. M. Santos, J. L. Capelo, O. N. Faza, E. Bertolo and C. Lodeiro, Inorg. Chem. Commun., 2009, 12, 905.

59 V. B. Bojinov and I. P. Panova, Dyes and Pigments, 2009, 80, 61.

60 W. Lin, L. Yuan, Z. Cao, J. Feng and Y. Feng, Dyes and Pigments, 2009, 80, 14.

61 H. S. Jung, P. S. Kwon, J. W. Lee, J. I. Kim, C. S. Hong, J. W. Kim, S. Yan, J. Y. Lee, J. H. Lee, T. Joo and J. S. Kim, J. Am. Chem. Soc., 2009, 131, 2008.

62 N. C. Lim, S. V. Pavlova and C. Brückner, Inorg. Chem., 2009, 48, 1173.

63 X. Wang, W. Zheng, H. Lin, G. Liu, Y. Chen and J. Fang, Tetrahedron Lett., 2009, 50, 1536.

64 A. Basoglu, S. Parlayan, M. Ocak, H. Alp, H. Kantekin, M. Ozdemir and U. Ocak, J. Fluoresc., 2009, 19, 655

65 A. Helal and H.-S. Kim, Tetrahedron Lett., 2009, 50, 5510.

66 S. Cao, H. Li, T. Chen and J. Chen, J. Solution. Chem., 2009, 38, 1520.

67 B. A. Wong, S. Friedle and S. J. Lippard, Inorg. Chem., 2009, 48, 7009.

68 B. A. Wong, S. Friedle and S. J. Lippard, J. Am. Chem. Soc., 2009, 131, 7142.

69 I. Grabchev, P. Bosch, M. McKenna and D. Staneva, J. Photochem. Photobiol. A. Chem., 2009, 201, 75.

70 S. Annamalai, I.-T. Ho, K.-C. Chang, G.-H. Lee, Y.-H. Liu and W.-S. Chung, Chem. Eur. J., 2009, 15, 6152. 